\title{
Title: Effortless or less effort? Effects of tracks on students' engagement
}

\author{
Jonas Dockx ${ }^{* 1}$, Naomi Van den Branden ${ }^{1}, \&$ Bieke \\ De Fraine ${ }^{1}$ \\ ${ }^{1}$ Centre for Educational Effectiveness and \\ Evaluation, Faculty of Psychology and Educational \\ Sciences, KU Leuven, Leuven, Belgium
}

*Corresponding author information: Jonas Dockx, Centre for Educational Effectiveness and Evaluation, Dekenstraat 2 box 3773, 3000 Leuven, Belgium (e-mail: jonas.dockx@kuleuven.be).

\begin{abstract}
:
Background. It is found that assigning students to a lower track during secondary education negatively affects their academic performance. As an explanation, it is often mentioned that an anti-school culture in lower tracks undermines students' effort and involvement.
\end{abstract}

Aims. This study assessed whether going to a lower track affects student engagement. For if an anti-school culture is to blame for limiting lower track students' performance, lower track assignment should reduce engagement.

Sample. A sample of a longitudinal cohort study during secondary education in Flanders (northern Belgium) was used to describe development in engagement with $n=5417$ students in 46 schools. Four tracks were investigated across four school years.

Method. Two main methodological challenges were present in this study, different student intake in each track and many students changing from a higher to lower track over time. 
Accordingly, we used inverse probability treatment weights with marginal structural mean models to account for different student intake and track changes. A comparison was made per pair of tracks that are hierarchically consecutive by matching students who were comparable across these tracks. Accordingly, there were three pairwise comparisons.

Results. It was never found that being continuously in lower track negatively affects engagement. Only for one pairwise comparison there was evidence that students who changed from the higher to lower track had lower engagement.

Conclusions. We rejected the hypothesis that lower tracks negatively affect student engagement. This makes the antischool culture as an explanation for lower track assignment negatively affecting academic performance implausible.

\section{Keywords:}

Tracking, marginal structural model, behavioural engagement, emotional engagement, vocational education

\section{Acknowledgements:}

This research was funded by the Flemish Policy Research Centre for Education. 


\section{Background}

In most education systems tracking is used during secondary education (OECD, 2012, pp. 57-58), placing students into different groups called tracks according to ability and interest (e.g., Trautwein, Lüdtke, Marsh, Köller, \& Baumert, 2006; Van de Werfhorst \& Mijs, 2010). The assignment of students into separate tracks has been linked to increased inequality in academic performance (e.g., Van de Werfhorst \& Mijs, 2010). An often cited explanation is that in lower tracks an anti-school culture exists, which limits effort and involvement, which in its turn limits learning progress in lower tracks (e.g., Carbonaro, 2005, p. 4; Van Houtte, 2016, pp. 874-875).

This study tests the anti-school culture hypothesis by assessing if being assigned to a lower track negatively affects school engagement. Inverse probability treatment weights with marginal structural mean models were used to control for differences in student intake between tracks and track changes across school years. A Flemish dataset was used for describing the development of school engagement during the first four years of secondary education. The same dataset was also used for studies on the effects of tracks on academic performance (Dockx, De Fraine, \& Vandecandelaere, 2018) and academic self-concept (Dockx, De Fraine, \& Vandecandelaere, 2019). However, in this 
study a new year's data has been added.In the following sections, we describe literature on tracking, anti-school culture and school engagement in more detail.

\section{Tracking}

Tracking allows instructional practices to be tailored to the specific abilities and needs of more homogeneous student groups (e.g., Hanushek \& Wößmann, 2006). Furthermore, it also allows for the development of specialized skillsets, which are required by the labour market (e.g., Kelly \& Price, 2011; Shavit \& Müller, 2000; Van de Werfhorst \& Mijs, 2010). Hence, policymakers have several reasons to implement tracking at some time point during secondary education.

Two types of tracking systems are often distinguished, the early tracking system and the late tracking system (e.g., Van de Werfhorst \& Mijs, 2010). The early tracking system places students in different tracks at a young age (i.e., 12 years or younger), whereas the late tracking system places students in different tracks at an older age (i.e., 14 years or older, Brunello \& Rocco, 2017; Schütz, Ursprung, \& Wößmann, 2008; Shavit \& Müller, 2000). Usually, tracks are hierarchically organized, which leads to a distinction between higher and lower tracks, and is based on the average academic performance of students. Most studies comparing education systems have shown that education systems 
with early tracking increase inequality in academic performance between students compared to education systems with late tracking (e.g., Ammermüller, 2005; Bauer \& Riphahn, 2006; Brunello \& Checchi, 2007; Hanushek \& Wößmann, 2006; Horn, 2009; Lavrijsen \& Nicaise, 2015; Marks, 2005; Schütz et al., 2008; Wößmann, 2008), but not all (e.g., Waldinger, 2007). Studies that investigated educational reform of tracking practices also find that early tracking increases inequality in academic performance (Hall, 2012; Jakubowski, Patrinos, Porta, \& Wiśniewski, 2016; Kerr, Pekkarinen, \& Uusitalo, 2013; Malamud \& Pop-Eleches, 2011; Piopiunik, 2014). Hence, early tracking increases inequality in academic performance.

The larger inequality in academic performance in early tracking systems is typically explained by students being allocated to tracks based on their academic performance and their socioeconomic background (e.g., Erikson, Goldthorpe, Jackson, Yaish, \& Cox, 2005; Jackson et al., 2007; Kloosterman, Ruiter, De Graaf, \& Kraaykamp, 2009). Accordingly, studies show that students with lower academic abilities and disadvantageous socioeconomic backgrounds are placed in lower tracks, which negatively affect academic performance (e.g., Becker, Lüdtke, Trautwein, Köller, \& Baumert, 2012; Guill, Lüdtke, \& Köller, 2017; Gustafsson, 2008; Korthals \& Dronkers, 2016; Retelsdorf, 
Becker, Köller, \& Möller, 2012). Using the same sample as this study, a study in Flanders also found that lower track placement negatively affects academic performance (Dockx et al., 2018). Therefore, increased inequality in academic performance is explained by the separation of student across lower and higher tracks, with lower track allocation negatively affecting academic performance. However, the exact mechanisms that lead to lower academic performance in lower tracks remain unclear.

Between education systems with explicit tracking, there are many differences. As stated in the former paragraphs, it is clear that the age of when tracking starts can differ. Other differences include whether track assignment depends on standardized tests (e.g., Bol, Witschge, Van de Werfhorst, \& Dronkers, 2014; Tieben, de Graaf, \& de Graaf, 2010; Trautwein et al., 2006), whether different tracks retain similarities in their curriculum or whether they are highly specialized (e.g., Shavit \& Müller, 2000), whether and to what extent students can change between tracks (e.g., Akkerman, 2011; Becker et al., 2016; OECD, 2016a), and whether each class belongs to a separate track or whether each school belongs to a separate track (e.g., Trautwein et al., 2006; Van de Werfhorst \& Mijs, 2010). Hence, when assessing the effects of tracks in different education systems, it should be kept in mind that the structures of tracks can differ in key characteristics. 


\section{Anti-school culture}

The effects of tracks on students' outcomes are usually attributed to wide-ranging differences in learning environments provided by the different tracks. First, tracks differ in student composition, for students with different academic abilities, interests and socioeconomic backgrounds go to different tracks (Maaz, Trautwein, Lüdtke, \& Baumert, 2008; Trautwein et al., 2006). Accordingly, it is assumed that the student composition of a class or schools affects student outcomes. However, not only student composition is a plausible explanation of track effects. Higher tracks are also found to be more academically challenging (e.g., Salmela-Aro, Kiuru, \& Nurmi, 2008; Stevens \& Vermeersch, 2010). Research has shown that cognitive activating instructions and higher levels of problem solving are more prevalent in higher tracks, whereas discipline and rote memorization are emphasized in lower tracks (Kunter \& Baumert, 2006; Retelsdorf, Butler, Streblow, \& Schiefele, 2010; Van Houtte, 2004). Baumert et al. (2010) also found that teachers in higher tracks have more (pedagogical) content knowledge. Note that the hypotheses on track effects in this paragraph are plausibly related, with pedagogical response resulting from classroom composition and vice versa (e.g., Gamoran, 1992; Ireson, Hallam, \& Plewis, 2001). 
In this paper we tested the hypothesis that lower tracks limit learning progress, because lower tracks have an anti-school culture. While there is no generally agreed upon definition of an anti-school culture, it is often described as students being opposed to the school system (e.g., Carbonaro, 2005, p. 4; Van Houtte, 2016, pp. 874-875). This is reflected in lower track students showing less effort and setting less ambitious academic goals, which limits learning progress.

The existence of an anti-school culture in lower tracks has typically been explained by using the differentiation-polarization theory (Hargreaves, 1967; Lacey, 1966). This theory states that students experience being assigned to a lower track as a failure, for this indicates that they did not meet the academic demands of the higher tracks. Accordingly, research shows that students are aware of the status of their student group (e.g., Abraham, 2008; Susan Hallam \& Ireson, 2006, 2007) and consider going to a lower track as a negative choice (Ainsworth \& Roscigno, 2005). Because educational attainment can no longer give status to these students, they start looking for alternatives sources of status (Van Houtte, 2006a), which results in an anti-school culture.

Related to the differentiation-polarization theory is how students appraise the future rewards education can give (Van Houtte, 2006a). Lower tracks typically prepare students for less 
esteemed and lower wage jobs (e.g., Brunello \& Rocco, 2017;

Schütz et al., 2008; Shavit \& Müller, 2000), whereas higher tracks

offer more pathways to higher education (e.g., Wang \& Eccles, 2012; Wolbers, 2007). Hence, lower tracks students expect fewer future rewards because of education. Van Houtte (2016) indeed showed that lower track students have a higher sense of futility, the feeling of no control over success in education. In sum, an antischool culture results from lower track students expecting fewer rewards from education.

Alternative explanations for an anti-school culture can be given as well. For example, lower tracks are more likely to attract students from disenfranchised backgrounds who may already have developed anti-school attitudes prior to track allocation. This higher prevalence of anti-school attitudes may create a compositional effect, which affects all lower track students (Müller \& Hofmann, 2016). Another alternative explanation is that teachers in lower tracks have lower expectations of students and set less ambitious goals, and students will act accordingly (Abraham, 2007; Van Houtte, 2006b). Hence, this may lead to an anti-school culture as well.

Note that it could also be hypothesized that allocation to a lower track is beneficial. The big-fish-little-pond theory states that students compare themselves to other students in their school or 
classroom to appraise their own academic ability. This selfappraisal is called academic self-concept (Huguet et al., 2009). Accordingly, students will appraise themselves more positively when they are allocated to a track where students have lower academic abilities instead of a track where students have higher academic abilities. There is indeed some evidence that being allocated to a lower track positively affects this academic selfconcept (e.g., Arens \& Watermann, 2015; Becker et al., 2014; Chiu et al., 2008; Liu, Wang, \& Parkins, 2005; Mulkey, Catsambis, Steelman, \& Crain, 2005; Preckel \& Brüll, 2010; Trautwein, Lüdtke, Marsh, \& Nagy, 2009). Using the same sample as this study, Dockx, De Fraine and Vandecandelaere (2019) also found that lower track placement generally has a positive effect on academic self-concept in Flanders. However, it is unknown whether the more positive academic self-concept caused by lower track allocation may also positively affect engagement.

In sum, an anti-school culture is often used to explain how lower tracks limit the learning progress of students. However, there are different theories on why an anti-school culture would exist in these tracks.

\section{School engagement}


The main challenge in assessing whether students have been affected by an anti-school culture is how that lack of effort and involvement should be operationalized. In educational research, the concept of school engagement is typically used to describe a student's effort and involvement. In the following paragraphs we explore this concept.

School engagement has been described as a range of attitudes and behaviours that reflect the level of involvement and effort of students in school. Engaged students seek and participate in those activities that make them successful in their learning activities (e.g., Fredricks, 2011; Johnson et al., 2001; Skinner et al., 2008, 2009). Originally, there was not one interpretation of engagement, and different constructs were assessed. Fredricks, Blumenfeld, \& Paris (2004) integrated these different constructs into one three-dimensional construct of engagement, consisting of a behavioural, an emotional and a cognitive component. Behavioural school engagement refers to the level of positive behaviours and active involvement in the learning activities. This dimension has been the focus of research on student conduct and on-task behaviour. Emotional school engagement describes the student's positive emotions and attitudes towards teachers, classmates and school in general. This dimension has been the focus of research on student attitudes, interests and values. 
Cognitive school engagement describes a student's level of conscious investment in the learning activities. This dimension has been the focus of research on motivational goals and self-regulated learning (e.g., Fredricks, 2011; Fredricks et al., 2004; Meece, Blumenfeld, \& Hoyle, 1988; Skinner et al., 2009; Turner et al., 2002).

Note that a form of negative school engagement can be described as well, called disaffection (Skinner et al., 2009) or disengagement (Eccles, 2004). It encompasses a range of negative attitudes and behaviours such as: lack of initiation, lack of effort, mental withdrawal and giving up. It is also multidimensional with a behavioural, emotional and cognitive component. However, discussion remains whether school engagement and disaffection are on a single continuum or (partly) represent different concepts (e.g., Jimerson, Campos, \& Greif, 2003).

Research has shown that school engagement outcomes generally decline through students' school careers, with the steepest declines reported during secondary education (e.g., Skinner \& Pitzer, 2012; Wylie \& Hodgen, 2012). This decline has been attributed to a mismatch between the developmental needs during adolescence and the educational environment (e.g., Christenson, Reschly, \& Wylie, 2012; Eccles et al., 1993). Furthermore, studies have shown that during secondary education 
school engagement predicts both academic performance and dropout (e.g., Archambault et al., 2009; Fall \& Roberts, 2012; Fredricks et al., 2004; Green et al., 2012; Martin et al., 2012; Reschly et al., 2008; Wang \& Fredricks, 2014; Wang \& Holcombe, 2010). Evidence also shows that students' school engagement can be influenced by teachers and schools (Appleton, Christenson, \& Furlong, 2008). Furthermore, there is evidence that supporting one of the three basic needs according to Self-Determination Theory may benefit engagement (e.g., Reeve, 2012).

\section{This study}

The goal of this study was to investigate if being allocated to a lower track negatively affects effort and involvement within the Flemish education system. This research question derived from studies on tracking which often mention that the anti-school culture in lower tracks negatively affects effort and involvement, which in its turn negatively affects academic performance. In Flanders, there is also a prevailing sentiment that going to a lower track will negatively affect engagement. However, this idea has not been empirically investigated.

Flemish education is an early tracking system where students choose freely between four tracks at age 12 (OECD, 2012, p. 57). These tracks are hierarchically organized by the average 
academic abilities of students (Van Houtte, 2004). While track

choice is free, students who do not meet the needs of higher track at the end of school year will be forced down the hierarchy of tracks. This change of a higher track to a lower track in the hierarchy is often described as the "educational waterfall" (Boone \& Van Houtte, 2013). Accordingly, many students finish their secondary education one track lower than their initial track choice. From high to low these are the classical track, the modern track, the technical track and the vocational track. The classical and modern track mainly provide pathways to tertiary education, but they do not prepare for a transition to the labour market. The technical track offers pathways to both tertiary education and a direct transition labour market. The vocational track primarily prepares for a direct transition to the labour market. Tracks are organized at the class-level, and all classmates are in the same track.

The research question of this study was if being in a lower track in Flanders affects students' engagement. This research question comes from the literature on tracking where lower track allocation is assumed to negatively affect students' effort and involvement. We used school engagement measures for assessing the level of effort and involvement. We considered these to be good measures for effort and involvement, for the literature on 
engagement fits the description of effort and involvement well. Therefore, we estimated the effect of being in a lower track on engagement, compared to being in a higher track. Because students can change from a higher to lower track between school years, the effect of going to a lower track is not a single estimate. Rather, the effect of a lower track should be estimated for students who always are in the lower track and students who change to the lower track between school years.

Any estimated effect of being allocated to a lower track would be biased if we did not account for tracks attracting students with different background characteristics. On average, higher tracks attract students with higher academic performance and more advantageous socioeconomic backgrounds. Moreover, the students who change from a higher to lower track over time in Flemish education tend to be students with lower academic performance. Consequently, we used marginal structural mean models (MSMMs), a method which uses inverse probability weighting (IPW) to reweight datasets so no differences prior to initial track allocation can bias the effect. Furthermore, this method accounted for the track changes that occur in Flemish secondary education over time. 
Our main hypothesis was that lower track placement negatively affects students' engagement. This was based on the idea of an anti-school culture in lower tracks. Our second hypothesis was that track change will also negatively affect engagement. This was based on the prevailing sentiment in Flemish education. In the following section, the sample and methods are described in more detail.Method

\section{Sample}

We used data from a study that follows a cohort of 6328 students in 48 schools (LiSO-project, 2018). A subsample was taken where students from de-tracked schools, students in a sports or arts program and students who were redoing their first year in secondary education were removed. Hence, our final subsample consisted of 5417 students. At the start of secondary education 1419 students were in the classical track, 2229 were in the modern track, 1033 students were in the technical track and 736 students were in the vocational track.

There were five measurement occasions, as shown in Figure 1: the start of secondary education September 2013 (T0), the end of the first year of secondary education May 2014 (T1), the end of the second year of secondary education May 2015 (T2), the end of the third year of secondary education May 2016 (T3), and the end of the fourth year of secondary education May 2017 (T4). 
[Figure 1]

\section{Variables}

\section{Treatment variable}

The treatment variable was track allocation $\left(Z_{t}\right)$. Pairwise comparisons were made between tracks that are consecutive in the hierarchy of tracks. It was not possible to compare nonconsecutive tracks, due to the absence of comparable students (this will be further explained in the section 'Weighting procedure'). Lower track allocation was the active treatment condition $\left(Z_{t}=1\right)$, whereas higher track allocation was the control condition $\left(Z_{t}=0\right)$. Three comparisons were made: the classical track with the modern track, the modern track with the technical track, and the technical track with the vocational track. For each comparison of two tracks five track allocation histories were distinguished: staying in the higher track continuously $(0,0,0,0)$, starting in the higher track but changing to the lower track after T3 $(0,0,0,1)$, starting in the higher track but changing to the lower track after $\mathrm{T} 2(0,0,1,1)$, starting in the higher track but changing to the lower track after T1 $(0,1,1,1)$ and staying in the lower track continuously $(1,1,1,1)$. 


\section{Outcomes}

School engagement was operationalized with a measure for behavioural school engagement and a measure for emotional school engagement. Multiple group factor analyses were used to investigate measurement invariance across measurement occasions (Baumgartner \& Steenkamp, 2006; Cheung \& Rensvold, 2002). This implied assessing whether factor loadings and means of the indicators can be held equal over time and across tracks with sufficient model fit. The cutoff criteria from $\mathrm{Hu}$ and Bentler's (1999) were used for fit indices CFI, TLI and RMSEA.

Behavioural school engagement was measured with five items, and emotional school engagement was measured with four items. Both measures were part of a student questionnaire which was conducted at T0, T1, T2, T3 and T4. The items were Dutch translations of the items of an English measure (Skinner et al., 2009). Factor analyses showed that a one-factor structure with assumed measurement invariance fitted well for behavioural school engagement and no item loading or intercept had to be unconstrained $(\mathrm{CFI}=.97, \mathrm{TLI}=.97, \mathrm{RMSEA}=.06)$. For emotional school engagement one item intercept had to be unconstrained at T0 to achieve satisfactory model fit $(\mathrm{CFI}=.98, \mathrm{TLI}=.98, \mathrm{RMSEA}$ $=.05)$. Composite reliabilities ranged from 0.78 to 0.85 for behavioural school engagement, for emotional school engagement 
they ranged from 0.78 to 0.80 . Maximum a posteriori (MAP)

estimation was used for student factor scores with a zero mean and unit variance.

\section{Independent variables}

To procure unbiased estimates of track effects we needed to account for all differences between students that predict both track change and the outcome at each time point. In literature on MSMMs this is referred to as the sequential conditional exchangeability assumption (Robins \& Hernán, 2009). Most authors agree that all variables that predict both the treatment (i.e., track allocation and track change in this study) and the outcome (i.e. school engagement in this study) should be included. If sample size allows it, all variables related to the outcome should also be included (e.g., Brookhart et al., 2006; Myers et al., 2011; Stuart, 2010). Hence, we included those variables that predict school engagement, the initial track allocation and track changes. We used 25 variables, which are discussed in the following paragraphs and shown in Table 1. 


\section{Academic performance}

Three measures of academic performance were used: a mathematics test, a Dutch reading comprehension test and a French test. Each test consisted of multiple-choice items and open questions. Item Response Theory (IRT) with 2-parameter and 3parameter models was used. Warm's weighted likelihood estimation (Warm, 1989) was used for estimating student ability scores. Mathematics tests were conducted at T0, T1, T2 and T3 with the Cronbach's Alphas ranging from 0.83 to 0.87. A Dutch reading comprehension test was conducted at $\mathrm{T} 0$ with a Cronbach's Alpha of 0.82 . A French test was conducted at T0 with a Cronbach's Alpha of 0.79 .

\section{Biographical background}

Two variables from governmental records were used. The first variable indicates whether the student is a boy. The second variable indicates whether the student is older than normally progressing students.

\section{Socioeconomic background}

Socioeconomic status was modeled with a Nominal Response Model (Bock, 1972) based on seven indicators: (1 \& 2) diploma father and diploma mother, $(3 \& 4)$ employment status father and employment status mother, (5 \& 6) occupational level father and occupational level mother and (7) family income. These 
indicators were acquired from a parent questionnaire conducted at T0. Expected A Posteriori (EAP) estimation was used for computing factor scores with an empirical reliability of 0.87 .

Three variables from governmental records were also used. The first variable indicates whether a student's family is eligible for a governmental financial grant due low family income. The second variable indicates whether the mother has not attained a diploma of secondary education. The third variable indicates whether the student does not speak Dutch with more than one family member.

\section{Psychosocial development}

For psychosocial development repeated measurements of engagement, disengagement, academic self-concept, motivation, mindset, school wellbeing and interest were conducted at T0, T1, T2 and T3 with a student questionnaire. All these measures were on a five-point response scale, which ranged from "not true" to "true". Most were Dutch translations of English measures. MAP estimation was used for student factor scores. 
Behavioural and emotional school engagement were already discussed in the outcomes section. Behavioural disengagement and emotional disengagement were also assessed. These originated from the same source as the engagement measures (Skinner et al., 2009). Academic self-concept was assessed with measures for global academic self-concept and domain-specific self-concepts for mathematics, Dutch and French. These came from the Self-Description Questionnaire III (Marsh \& O'Neill, 1984) and shortened Self-Description Questionnaire II (Marsh, Ellis, Parada, Richards, \& Heubeck, 2005). Composite reliabilities ranged from 0.77 to 0.84 for general academic selfconcept, from 0.89 to 0.92 for self-concept in mathematics, and from 0.85 to 0.88 for self-concept in Dutch. Student motivation was assessed with measures for controlled motivation and autonomous motivation. These came from the Academic SelfRegulation Questionnaire (SQR-A, Ryan \& Connell, 1989). Composite reliabilities ranged from 0.74 to 0.78 for controlled motivation, and from 0.78 to 0.81 for autonomous motivation. Mindset was assessed with the Theory of Intelligence Scale (Dweck, Chiu, \& Hong, 1995). The composite reliability of mindset ranged from 0.55 to 0.73 . School wellbeing was assessed with a measure of Dutch origin (Vorst \& Smits, 2010). The composite reliability of school wellbeing ranged from 0.80 
to 0.85. Interest was assessed for mathematics, Dutch, French and technology (Denissen, Zarrett, \& Eccles, 2007). SpearmanBrown Coefficients ranged from 0.83 to 0.91 for interest in mathematics, from 0.81 to 0.88 for interest in Dutch, from 0.86 to 0.88 for interest in French, and from 0.92 to 0.96 for interest in technology.Marginal structural mean model

\section{Background}

The goal of a marginal structural model (e.g., Vandecandelaere, Vansteelandt, De Fraine, \& Van Damme, 2016) is to construct comparable groups of respondents (i.e., students) across treatment conditions (i.e., attending the higher track or the lower track) at each time point that a treatment exposure can occur (i.e., track changing between school years). To achieve this, inverse probability treatment weighting (IPTW; Austin, 2011) is used. IPTW's main rationale is that when estimating the treatment probabilities on a set of covariates, the estimated probabilities summarize the pretreatment differences in covariates between treatment conditions (Imbens, 2000, p. 708; Rosenbaum \& Rubin, 1983). By weighting with the inverse of these probabilities each treatment condition is made to resemble the population prior to the treatment exposure. Accordingly, the MSMM estimates the average outcome if the entire population would have been 
allocated to a certain treatment history. This estimated average outcome is called the marginal mean (Robins \& Hernán, 2009).

The application of a MSMM to estimate the marginal means of each treatment history consists of three main steps (e.g., Vandecandelaere, et al., 2016). First, a structural model for the marginal means is defined. Second, weights are estimated. Third, a Horvitz-Thompson type estimator with the weighs is used for estimating the structural model. The differences between the marginal means of the structural model are unbiased if the sequential conditional exchangeability assumption holds (Robins \& Hernán, 2009). We describe each of these steps in the following sections.

\section{Structural model}

As a first step of applying the MSMM we linked the marginal mean of each treatment history to a structural model. The marginal mean here is either behavioural school engagement or emotional school engagement. For the marginal mean at measurement occasion $\mathrm{T} 4$ we have the following equation:

$$
\begin{aligned}
& \mathrm{E}\left[Y_{4}\left(z_{1}, z_{2}, z_{3}, z_{4}\right)\right]=\beta_{0}+\beta_{1} z_{1} z_{2} z_{3} z_{4}+ \\
& \beta_{2}\left(1-z_{1}\right) z_{2} z_{3} z_{4}+\beta_{3}\left(1-z_{1}\right)\left(1-z_{2}\right) z_{3} z_{4}+ \\
& \beta_{4}\left(1-z_{1}\right)\left(1-z_{2}\right)\left(1-z_{3}\right) z_{4}(1)
\end{aligned}
$$

In this equation $\mathrm{E}\left[Y_{4}\left(z_{1}, z_{2}, z_{3}, z_{4}\right)\right]$ is the marginal mean, and parameters $\beta_{1}, \beta_{2}, \beta_{3}$ and $\beta_{4}$ respectively describe the average 
treatment effects of track allocation histories $(1,1,1,1),(0,1,1,1)$, $(0,0,1,1)$ and $(0,0,0,1) . \beta_{0}$ is therefore equal to the track allocation history of always being in the higher track $(0,0,0,0)$. Note that for the marginal means at measurement occasions T1, T2 and T3 equivalent structural models were specified.

\section{Weighting procedure}

The second step of applying the MSMM was the estimation of weights in order to remove pretreatment differences across treatment conditions. There were four time points of treatment exposure: T1, T2, T3 and T4. Accordingly, for each time point a time-specific weight was estimated. The total weight at $\mathrm{T} 4, \overline{S W}_{4}$, therefore was the product of time-specific weights, which are both described the following equation:

$$
\begin{array}{r}
\overline{S W}_{4}=S W_{1} * S W_{2} * S W_{3} * S W_{4}= \\
\frac{\mathrm{P}\left[Z_{1}=1\right]}{\mathrm{P}\left[Z_{1}=1 \mid \boldsymbol{x}_{0}\right]} * \frac{\mathrm{P}\left[Z_{2}=1 \mid Z_{1}=0\right]}{\mathrm{P}\left[Z_{2}=1 \mid \boldsymbol{x}_{0}, \boldsymbol{l}_{1}, Z_{1}=0\right]} * \\
\frac{\mathrm{P}\left[Z_{3}=1 \mid Z_{2}=0\right]}{\mathrm{P}\left[Z_{3}=1 \mid \boldsymbol{x}_{0}, \boldsymbol{l}_{2}, Z_{2}=0\right]} * \frac{\mathrm{P}\left[Z_{4}=1 \mid Z_{3}=0\right]}{\mathrm{P}\left[Z_{4}=1 \mid \boldsymbol{x}_{0}, \boldsymbol{l}_{3}, Z_{3}=0\right]}(5)
\end{array}
$$

In this equation $\overline{S W}_{4}$ was the total weight at $\mathrm{T} 4$, and $S W_{1}$, $S W_{2}, S W_{3}$ and $S W_{4}$ were the time-specific stabilized weights. Each time-specific weight was estimated based on the baseline measure of the covariates measured at T0 $\left(x_{0}\right)$ and the repeated measures of the time-varying covariates $\left(\boldsymbol{l}_{\mathrm{t}-1}\right)$ measured prior to the track change. When a time-specific weight was not estimated for a 
student (i.e., student was already in the lower track), it was replaced by value one (i.e. the total weight is unchanged). Note that for the total weights $\overline{S W}_{1}, \overline{S W}_{2}$ and $\overline{S W}_{3}$ at T1, T2 and T3 respectively, it was only necessary to multiply time-specific weights until that measurement occasion.

Before estimating weights, we assessed the area of common support between the different track allocation histories of a track comparison. This was achieved by estimating the propensity score of being continuously in the higher track. The overlap in the resulting propensity scores were then used to assess the area of common support (Steiner \& Cook, 2013). To prevent extreme weights, students with probabilities close to either one or zero were removed from the sample prior to estimating weights. We used a minimum of 0.05 and a maximum of 0.95 as cutoff values (e.g., Crump, Hotz, Imbens, \& Mitnik, 2009). This step will be shown first in the results section.

Furthermore, to attain stable weights estimates we chose not to use the entire history of time-varying covariates, but only their values at T0 (i.e., the baseline measures) and their values directly prior to the track allocation. This appeared to be enough to balance the entire covariate history and stabilize the weight estimation. To estimate the propensity score we used generalized boosted regression models (GBMs, McCaffrey, Ridgeway, \& 
Morral, 2004), which is considered best practice for propensity score estimation (e.g., Stuart, 2010). However, for the technical and vocational track comparison we used the covariates as linear predictors, for this lead to a better balance. We also used $99^{\text {th }}$ percentile truncation (e.g., Lee, Lessler, \& Stuart, 2011). The twang 1.5 package (Ridgeway, McCaffrey, Morral, Griffin, \& Burgette, 2017) in R 3.4.3 was used for weight estimation.

We assessed balance in the covariates after applying the weights with standardized mean differences of covariates (SMDs). The SMD is the difference between two covariate means of track allocation histories, divided by the pooled $S D$ of both track allocation histories (Rubin, 2001). The SMDs were assessed before and after applying weights. Mean SMDs should be no higher than 0.05 while SMDs of specific covariates as a rule of thumb should not exceed 0.25 (Caliendo \& Kopeinig, 2008).

\section{Estimation}

The third step of applying the MSMM was fitting the structural models as a generalized linear model. The model is estimated with the time-varying outcome on the left hand-side, and the combination of treatment-history indicators with time point indicators on the right-hand side. We used GEEs with the NewtonRaphson algorithm and specified an independent correlation matrix (Liang \& Zeger, 1986) with sandwich standard errors (Joffe, Ten 
Have, Feldman, \& Kimmel, 2004). Using a non-independent correlation structure or multilevel models would bias results by making outcome measurements dependent on future treatment exposures (Robins, Hernan, \& Brumback, 2000, p. 554). To examine differences between track allocation histories at each time point, contrasts were tested using one degree of freedom Wald tests (Kuhn, Weston, Wing, \& Forester, 2016). The geepack 1.2-1 package in R 3.4.3 was used for estimation (Højsgaard, Halekoh, $\&$ Yan, 2006). Cohen's $d$ was used for effect size interpretation (Cohen, 1977).

\section{Missing values}

The rates of missingness for the track allocation histories of interest were $2.98 \%, 14.17 \%, 8.18 \%, 12.86 \%$, and $15.87 \%$ (only outcomes) at T0, T1, T2, T3 and T4 respectively. We used multiple imputation by chained equations for missing values in the outcomes and covariates (Schafer \& Graham, 2002) with the package mice 2.30 (van Buuren \& Groothuis-Oudshoorn, 2011) in R 3.4.3. This should result in unbiased and efficient estimates under the missing at random assumption (MAR, e.g., Moodie, Delaney, Lefebvre, \& Platt, 2008). We estimated ten imputed datasets, and combined the results as described by Rubin's (1987) rules. The average relative efficiencies for contrasts at $\mathrm{T} 4$ was $99.12 \%$ for the classical and modern track comparison, $98.23 \%$ for 
the modern and technical track comparison, and $97.59 \%$ for the technical and vocational track comparison.

There were also students who did not have a track allocation history as described in the 'Treatment variable' section, but at some time point went to a sports program, arts program, special method program, special education, changed track multiple times or changed to a track not part of the comparison. Simply removing these students from the analysis could bias results. Therefore, these students were included in the analysis up until the time point they went to an alternative track allocation history, from that time point they were considered censored. Censoring weights for these students were estimated just as IPTW for the MSMM, but now the probability of being censored was estimated. The final weights used in the analysis were a product of the IPTW weights and censoring weights.

\section{Results}

\section{Balance after weighting}

Figure 2 shows the overlap in logit propensity scores of higher track allocation between track allocation histories of each comparison. Substantial overlap exists, but for each comparison very low propensity scores and very higher propensity scores occurred. Accordingly, by applying the cut-off values of .05 and .95 , students were removed from the dataset. The resulting 
sample size for each comparison across time points is shown in Table 2.

[Figure 2]

[Table 2]

Figures 3, 4 and 5 show the absolute SMDs for each track comparison. Note that in the first panel of Figure 5, the unweighted absolute standardized mean difference for mathematics at T0 exceeds the x-axis' limit, for it had a value of 1.47. Table 3 shows the mean, minimum, and maximum of all SMDs after applying the weights. The results show a substantial reduction in the pretreatment differences between tracks. For the classical and modern track comparison, general academic self-concept measured direct prior to a track allocation slightly exceeds the .25 cutoff value at $\mathrm{T} 1, \mathrm{~T} 2$ and $\mathrm{T} 3$. The same is observed for the modern and technical track comparison, however at $\mathrm{T} 4$ there is remaining imbalance in mathematics self-concept and also mathematics performance. For the technical and vocational track comparison, imbalance remains for interest in technology and gender at T2 and T3. At T4 imbalance remains for self-concept in mathematics and mathematics performance. 
[Table 3]

[Figure 3]

[Figure 4]

[Figure 5]

\section{Analysis of track effects}

In the following paragraphs we describe the estimated contrasts across the three track comparisons. For brevity, we limit the description to general trends and the final contrast estimates at T4. Figures 6, 7 and 8 also show the development in behavioural school engagement and emotional school engagement for each track comparison. Note that across all outcomes and across all groups we only observe declines. Accordingly, we will describe whether the different groups of students decline more than the reference group, which is the group of students continuously in the higher track. The estimated contrasts are shown in Table 4, 5 and 6.

\section{Classical and modern track comparison}

For behavioural school engagement we see no substantial difference in the development between the group of students 
continuously in the higher track and the group of students continuously in the lower track. Hence, at T4 the contrast is not significant. The groups of students who changed from the higher to lower track do decline more. However, only the group of students who changed from the higher to lower track after T1 has a significant contrast at $\mathrm{T} 4$, but it has a trivial effect size.

For emotional school engagement we see no substantial difference in the development between the group of students continuously in the higher track and the group of students continuously in the lower track. Hence, at T4 the contrast is not significant. The groups of students who changed from the higher to lower track do decline more. Accordingly, the group of students who changed from the higher to lower track after T1 and the group of students who changed from the higher to lower track after T2 have significant contrasts at T4 with small effect sizes.

[Table 4]

[Figure 6]

\section{Modern and technical track comparison}

For behavioural school engagement there is no substantial difference in the development between the group of students 
continuously in the higher track and the group of students continuously in the lower track. Hence, at T4 the contrast is not significant. The groups of students who changed from the higher to lower track do decline more. However, only the group of students who changed from the higher to lower track after T2 has a significant contrast at $\mathrm{T} 4$, but it has a trivial effect size.

For emotional school engagement the group of students continuously in the lower track declines slightly more than the group of students continuously in the higher track. However, at T4 the contrast is not significant. Only the group of students who changed from the higher to lower track after T1 decline slightly more. Hence, at T4 their contrast is significant but with a trivial effect size.

[Table 5]

[Figure 7]

\section{Technical and vocational track comparison}

For behavioural school engagement there are some differences in the development between the group of students continuously in the higher track (technical track) and the group of students continuously in the lower track (vocational track), but at 
T4 no difference remains. Hence, at T4 the contrast is not significant. The groups of students who changed from the higher to lower track also show some difference in their development, but at T4 no differences remain.

For emotional school engagement there are some difference in the development between the group of students continuously in the higher track and the group of students continuously in the lower track, but at T4 no difference remains. Accordingly, at T4 the contrast is not significant. The groups of students who changed from the higher to lower track also show some difference in their development, but at $\mathrm{T} 4$ no differences remain.

[Table 6]

[Figure 8]

\section{Summary}

In sum, for the classical and modern track comparison we find that students who changed from the higher to lower track generally decline more in emotional school engagement. There is no substantial difference for behavioural school engagement. Students continuously in the classical track and modern track do not differ for both outcomes. For the modern and technical track 
comparison we find no substantial differences between student groups. Accordingly, for the technical and vocational track comparison we find no substantial differences between student groups.

\section{Discussion}

In this study we investigated whether being assigned to the lower track, either from the start of secondary education or after a track change, affects school engagement. Behavioural and emotional school engagement were compared between four tracks. Students were compared across pairs of tracks that were hierarchically consecutive, which lead to three pairwise track comparisons.

We generally do not find support for our hypothesis. Only for one out of three pairwise track comparisons we find evidence that students who start in the higher track but change to the lower track have lower school engagement than comparable students continuously in the higher track. However, there is never evidence that students continuously in the lower track have lower school engagement than comparable students in the higher track. Therefore, the hypothesis is rejected.

This finding is surprising given that an anti-school culture if often used as an explanation for lower tracks negatively affecting academic performance (e.g., Abraham, 2008; Müller \& Hofmann, 
2016; Van Houtte, 2006a). However, it should be noted that we assessed behavioural and emotional school engagement as an operationalization of anti-school norms. Behavioural school engagement describes the level of active involvement in the learning activities and emotional school engagement describes the positive emotions a student has toward to teachers, classmates and school in general. Contrarily, Van Houtte and Stevens (2015) measured the sense of futility, which can be defined as not believing it is possible to influence one's own success at school. Hence, a difference in operationalization may be the cause for the rejection of our hypothesis.

Our results are similar to the results of Dumont, Protsch, Jansen and Becker (2017), who investigated the effects of tracks on disengagement with the Maslach Burnout Inventory cynicism scale. Because students from the same track could receive different certificates, they could distinguish between the effect of the track as a social context and the effect of a certificate. The students were assessed just before they entered the labour market. Generally, they found that, given the same certificate, the track as a social context does not affect students' cynicism.

However, if anti-school culture cannot explain why lower tracks negatively affect academic performance, alternative explanations become more plausible. For example, higher tracks 
have more learning opportunities that are both cognitively

challenging and supported by adaptive teacher feedback, whereas lower tracks are more characterized by rote memorization and the disciplining of students (e.g., Baumert et al., 2010; Kunter \& Baumert, 2006; Retelsdorf, Butler, Streblow, \& Schiefele, 2010; Van Houtte, 2004). Accordingly, lower track are considered less academically challenging than higher tracks (e.g., Salmela-Aro, Kiuru, \& Nurmi, 2008; Stevens \& Vermeersch, 2010). In Germany teachers were also found to have more pedagogical content knowledge in higher tracks (Baumert et al., 2010; Krauss et al., 2008). Hence, alternative explanations of lower tracks negatively affecting academic performance are possible.

Note that these findings may only be applicable to Flanders. While earlier we solely distinguished tracking systems by the age when tracking starts, this is an oversimplification. Many aspects of tracking systems can differ across education systems such as whether the tracks are strongly specialized or retain general skills development (e.g.,Shavit \& Müller, 2000), the number of tracks (e.g., Bol \& van de Werfhorst, 2013), whether standardized tests determine assignment of students to tracks (e.g., Bol, Witschge, Van de Werfhorst, \& Dronkers, 2014; Tieben, de Graaf, \& de Graaf, 2010; Trautwein et al., 2006) and whether tracks are organized on the school-level or class-level (e.g., Trautwein et al., 
2006; Van de Werfhorst \& Mijs, 2010). Hence, tracking systems can differ substantially and this could affect the effects of a lower track on school engagement.

\section{Strengths and limitations}

A limitation of this study is that school engagement is only assessed for the behavioural and emotional component. This is a somewhat narrow operationalization of school engagement (e.g., Fredricks, 2011), for the cognitive component and disaffection are not included. However, keen readers will have noted that we have used behavioural disaffection and emotional disaffection as controls (Table 1). These measures were found to be unreliable and had only partial measurement invariance and we decided not to present their results here. However, we did estimate the effect of lower tack allocation on these disaffection measures at T4, which gave highly similar results as the school engagement measures. In our view, this indicated that the inclusion of disaffection measures would be of too limited value. The lack of a measure for cognitive school engagement is more problematic, given that it can act differently than emotional and behavioural school engagement (e.g., Wang \& Eccles, 2012).

Any estimate in this study is based on the assumption the no covariates remain that predict both lower track allocation and the school engagement (e.g., Rosenbaum \& Rubin, 1983). This 
assumption can never be tested (Steiner \& Cook, 2013). We argue though that by accounting for indicators of academic performance, socioeconomic background and psychosocial variables most bias should have been removed. Furthermore, unobserved variables that are correlated with the accounted for variables (Stuart, 2010) are accounted for as well.

The estimates in our study are limited to the area of common support between compared groups (e.g., Stuart, 2010). Our inferences can only apply to a population of students who are adequately represented in each group. Therefore, we only compared track allocation histories between tracks which are consecutive in the hierarchy of tracks. When comparing pairs of tracks, it was also necessary to remove respondents with very high and very low propensities prior to applying both methods. Accordingly, an estimate in this study should not be interpreted as the average effect as if the entire population was in a specific group.

Also note that the inferences in this study can not be simply generalized to other education systems. Tracks in Flemish education have unique characteristics, which may affect the outcomes of this study. Therefore, in other education systems different effects could be found. The only other study that shows 
that tracks do not affect engagement is the study of Dumont et al. (2017) in Germany.

\section{Conclusion}

In sum, we do not find that the assignment of students to a lower track affects school engagement. In addition, we only find limited evidence that changing from a higher to a lower track has a negative effect on school engagement. Therefore, In Flanders, the hypothesis that an anti-school culture causes lower tracks to negatively affect students' engagement is untenable. 


\section{References}

Abraham, J. (2007). Differentiating between and synthesizing quantitative, qualitative, and longitudinal research on polarized school cultures: a comment on Van Houtte (2006). Journal of Curriculum Studies, 39(5), 597-602. https://doi.org/10.1080/00220270701487624

Abraham, J. (2008). Pupils' perceptions of setting and beyond-a response to Hallam and Ireson. British Educational Research Journal, 34(6), 855-863.

https://doi.org/10.1080/01411920802044511

Ainsworth, J. W., \& Roscigno, V. J. (2005). Stratification, schoolwork linkages and vocational education. Social Forces, 84(1), 257-284. https://doi.org/10.1353/sof.2005.0087

Akkerman, Y. (2011). Overcoming school failure: policies that work, background Report for the Netherlands. Den Haag, the Netherlands.

Ammermüller, A. (2005). Educational Opportunities and the Role of Institutions. ZEW Discussion Paper, 5-44.

Appleton, J. J., Christenson, S. L., \& Furlong, M. J. (2008).

Student engagement with school: Critical conceptual and methodological issues of the construct. Psychology in the Schools, 45(5), 369-386. https://doi.org/10.1002/pits.20303 Archambault, I., Janosz, M., Fallu, J.-S., \& Pagani, L. S. (2009). 
Student engagement and its relationship with early high school dropout. Journal of Adolescence, 32(3), 651-670. https://doi.org/10.1016/j.adolescence.2008.06.007

Arens, A. K., \& Watermann, R. (2015). How an early transition to high-ability secondary schools affects students' academic selfconcept: Contrast effects, assimilation effects, and differential stability. Learning and Individual Differences, 37, 64-71. https://doi.org/10.1016/j.lindif.2014.11.007

Austin, P. C. (2008). A critical appraisal of propensity-score matching in the medical literature between 1996 and 2003. Statistics in Medicine, 27(12), 2037-2049. https://doi.org/10.1002/sim.3150

Bauer, P., \& Riphahn, R. T. (2006). Timing of school tracking as a determinant of intergenerational transmission of education. Economics Letters, 91(1), 90-97. https://doi.org/10.1016/j.econlet.2005.11.003

Baumert, J., Kunter, M., Blum, W., Brunner, M., Voss, T., Jordan, A., ... Tsai, Y.-M. (2010). Teachers' mathematical knowledge, cognitive activation in the classroom, and student progress. American Educational Research Journal, 47(1), 133-180. https://doi.org/10.3102/0002831209345157

Baumgartner, H., \& Steenkamp, J.-B. E. M. (2006). An extended paradigm for measurement analysis of marketing constructs 
applicable to panel data. Journal of Marketing Research, 43(3), 431-442. https://doi.org/10.1509/jmkr.43.3.431

Becker, M., Lüdtke, O., Trautwein, U., Köller, O., \& Baumert, J. (2012). The differential effects of school tracking on psychometric intelligence: Do academic-track schools make students smarter? Journal of Educational Psychology, 104(3), 682-699. https://doi.org/10.1037/a0027608

Becker, M., Neumann, M., \& Dumont, H. (2016). Recent developments in school tracking practices in Germany: An overview and outlook on future trends. Orbis Scholae, 10(3), 9-25. https://doi.org/10.14712/23363177.2017.8

Becker, M., Neumann, M., Tetzner, J., Böse, S., Knoppick, H., Maaz, K., ... Lehmann, R. (2014). Is early ability grouping good for high-achieving students' psychosocial development? Effects of the transition into academically selective schools. Journal of Educational Psychology, 106(2), 555-568. https://doi.org/10.1037/a0035425

Bock, R. D. (1972). Estimating item parameters and latent ability when responses are scored in two or more nominal categories. Psychometrika, 37(1), 29-51. https://doi.org/10.1007/BF02291411

Bol, T., \& van de Werfhorst, H. G. (2013). Educational systems and the trade-off between labor larket allocation and equality 
of educational opportunity. Comparative Education Review, 57(2), 285-308. https://doi.org/10.1086/669122

Bol, T., Witschge, J., Van de Werfhorst, H. G., \& Dronkers, J.

(2014). Curricular tracking and central examinations:

Counterbalancing the impact of social background on student achievement in 36 countries. Social Forces, 92(4), 15451572. https://doi.org/10.1093/sf/sou003

Boone, S., \& Van Houtte, M. (2013). Why are teacher recommendations at the transition from primary to secondary education socially biased? A mixed-methods research. British Journal of Sociology of Education, 34(1), 20-38. https://doi.org/10.1080/01425692.2012.704720

Brookhart, M. A., Schneeweiss, S., Rothman, K. J., Glynn, R. J., Avorn, J., \& Stürmer, T. (2006). Variable selection for propensity score models. American Journal of Epidemiology, 163(12), 1149-1156. https://doi.org/10.1093/aje/kwj149

Brunello, G., \& Checchi, D. (2007). Does school tracking affect equality of opportunity? New international evidence. Economic Policy, 22(52), 781-861. https://doi.org/10.1111/j.1468-0327.2007.00189.x

Brunello, G., \& Rocco, L. (2017). The labor market effects of academic and vocational education over the life cycle: Evidence based on a British cohort. Journal of Human 
Capital, 11(1), 106-166. https://doi.org/10.1086/690234

Caliendo, M., \& Kopeinig, S. (2008). Some practicial guidance for the implementation of propensity score matching. Journal of Economic Surveys, 22(1), 31-72. https://doi.org/10.1111/j.1467-6419.2007.00527.x

Carbonaro, W. (2005). Tracking, students' effort, and academic achievement. Sociology of Education, 78(1), 27-49. https://doi.org/10.1177/003804070507800102

Cheung, G. W., \& Rensvold, R. B. (2002). Evaluating goodnessof-fit indexes for testing measurement invariance. Structural Equation Modeling, 9(2), 233-255. https://doi.org/10.1207/S15328007SEM0902_5

Chiu, D., Beru, Y., Watley, E., Wubu, S., Simson, E., Kessinger, R., ... Wigfield, A. (2008). Influences of math tracking on seventh-grade students' self-beliefs and social comparisons. The Journal of Educational Research, 102(2), 125-136. https://doi.org/10.3200/JOER.102.2.125-136

Christenson, S. L., Reschly, A. L., \& Wylie, C. (2012). Handbook of research on student engagement. Boston, MA: Springer Science \& Business Media.

Cohen, J. (1977). Statistical power analysis for the behavioural sciences. New York City, NY: Academic press.

Crump, R. K., Hotz, V. J., Imbens, G. W., \& Mitnik, O. A. (2009). 
Dealing with limited overlap in estimation of average treatment effects. Biometrika, 96(1), 187-199. https://doi.org/10.1093/biomet/asn055

Denissen, J. J. A., Zarrett, N. R., \& Eccles, J. S. (2007). I like to do it, I'm able, and I know I am: Longitudinal couplings between domain-specific achievement, self-concept, and interest. Child Development, 78(2), 430-447. https://doi.org/10.1111/j.14678624.2007.01007.x

Dockx, J., De Fraine, B., \& Vandecandelaere, M. (2018). Does the track matter? A comparison of students' achievement in different Tracks. Journal of Educational Psychology, Advance online publication. https://doi.org/10.1037/edu0000305

Dockx, J., De Fraine, B., \& Vandecandelaere, M. (2019). Tracks as frames of reference for academic self-concept. Journal of School Psychology, 72, 67-90. https://doi.org/10.1016/j.jsp.2018.12.006

Dumont, H., Protsch, P., Jansen, M., \& Becker, M. (2017). Fish swimming into the ocean: How tracking relates to students' self-beliefs and school disengagement at the end of schooling. Journal of Educational Psychology, 109(6), 855-870. https://doi.org/10.1037/edu0000175

Dweck, C. S., Chiu, C., \& Hong, Y. (1995). Implicit theories and their role in judgments and reactions: A word from two 
perspectives. Psychological Inquiry, 6(4), 267-285.

https://doi.org/10.1207/s15327965pli0604_1

Eccles, J. S. (2004). Schools, academic motivation, and stage-

environment fit. In R. M. Lerner \& L. Steinberg (Eds.), Handbook of adolescent psychology, 2nd edition (pp. 125153). Hoboken, NJ: John Wiley \& Sons.

Eccles, J. S., Midgley, C., Wigfield, A., Buchanan, C. M., Reuman, D., Flanagan, C., \& Mac Iver, D. (1993). Development during adolescence: The impact of stage-environment fit on young adolescents' experiences in schools and in families. American Psychologist, 48(2), 90-101. https://doi.org/10.1037/0003066X.48.2.90

Erikson, R., Goldthorpe, J. H., Jackson, M., Yaish, M., \& Cox, D. R. (2005). On class differentials in educational attainment. Proceedings of the National Academy of Sciences of the United States of America, 102(27), 9730-9733. https://doi.org/10.1073/pnas.0502433102

Fall, A.-M., \& Roberts, G. (2012). High school dropouts: Interactions between social context, self-perceptions, school engagement, and student dropout. Journal of Adolescence, 35(4), 787-798.

https://doi.org/10.1016/j.adolescence.2011.11.004

Fredricks, J. A. (2011). Engagement in school and out-of-school 
contexts: A multidimensional view of engagement. Theory into Practice, 50(4), 327-335.

https://doi.org/10.1080/00405841.2011.607401

Fredricks, J. A., Blumenfeld, P. C., \& Paris, A. H. (2004). School engagement: Potential of the concept, state of the evidence. Review of Educational Research, 74(1), 59-109. https://doi.org/10.3102/00346543074001059

Gamoran, A. (1992). Synthesis of research: Is ability grouping equitable? Educational Leadership, 50(2), 1-18.

Green, J., Liem, G. A. D., Martin, A. J., Colmar, S., Marsh, H. W., \& McInerney, D. (2012). Academic motivation, self-concept, engagement, and performance in high school: Key processes from a longitudinal perspective. Journal of Adolescence, $35(5), 1111-1122$.

https://doi.org/10.1016/j.adolescence.2012.02.016

Guill, K., Lüdtke, O., \& Köller, O. (2017). Academic tracking is related to gains in students' intelligence over four years: Evidence from a propensity score matching study. Learning and Instruction, 47, 43-52. https://doi.org/10.1016/j.learninstruc.2016.10.001 Gustafsson, J. E. (2008). Schooling and intelligence: Effects of track of study on level and profile of cognitive abilities. In P. C. Kyllonen, R. D. Roberts, \& L. Stankov (Eds.), Extending 
intelligence: Enhancement and new constructs (pp. 31-49).

London, United Kingdom: Routledge.

Hall, C. (2012). The effects of reducing tracking in upper secondary school evidence from a large-scale pilot scheme. Journal of Human Resources, 47(1), 237-269. https://doi.org/10.3368/jhr.47.1.237

Hallam, S., \& Ireson, J. (2006). Secondary school pupils' preferences for different types of structured grouping practices. British Educational Research Journal, 32(4), 583599. https://doi.org/10.1080/01411920600775274

Hallam, S., \& Ireson, J. (2007). Secondary school pupils' satisfaction with their ability grouping placements. British Educational Research Journal, 33(1), 27-45. https://doi.org/10.1080/01411920601104342

Hanushek, E. A., \& Wößmann, L. (2006). Does educational tracking affect performance and inequality? differences-indifferences evidence across countries. The Economic Journal, 116(510), C63-C76. https://doi.org/10.1111/j.14680297.2006.01076.x

Hargreaves, D. H. (1967). Social Relations in a Secondary School. London, United Kingdom: Routledge \& Kegan Paul.

Højsgaard, S., Halekoh, U., \& Yan, J. (2006). The R package geepack for generalized estimating equations. Journal of 
Statistical Software, 15(2), 1-11.

https://doi.org/10.18637/jss.v015.i02

Horn, D. (2009). Age of selection counts: a cross-country analysis

of educational institutions. Educational Research and Evaluation, 15(4), 343-366.

https://doi.org/10.1080/13803610903087011

Hu, L., \& Bentler, P. M. (1999). Cutoff criteria for fit indexes in covariance structure analysis: Conventional criteria versus new alternatives. Structural Equation Modeling: A Multidisciplinary Journal, 6(1), 1-55. https://doi.org/10.1080/10705519909540118

Huguet, P., Dumas, F., Marsh, H. W., Régner, I., Wheeler, L., Suls, J., ... Nezlek, J. (2009). Clarifying the role of social comparison in the big-fish--little-pond effect (BFLPE): An integrative study. Journal of Personality and Social Psychology, 97(1), 156-170. https://doi.org/10.1037/a0015558

Imbens, G. W. (2000). The role of the propensity score in estimating dose-response functions. Biometrika, 87(3), 706710. https://doi.org/10.1093/biomet/87.3.706

Ireson, J., Hallam, S., \& Plewis, I. (2001). Ability grouping in secondary schools: Effects on pupils' self-concepts. British Journal of Educational Psychology, 71(2), 315-326. 
https://doi.org/10.1348/000709901158541

Jackson, M., Erikson, R., Goldthorpe, H., \& Yaish, M. (2007).

Primary and secondary effects in class differentials in educational attaintment: the transition to A-level courses in England and Wales. Acta Sociologica, 50(3), 211-229. https://doi.org/10.1177/0001699307080926

Jakubowski, M., Patrinos, H. A., Porta, E. E., \& Wiśniewski, J. (2016). The effects of delaying tracking in secondary school: evidence from the 1999 education reform in Poland. Education Economics, 24(6), 557-572. https://doi.org/10.1080/09645292.2016.1149548

Jimerson, S. R., Campos, E., \& Greif, J. L. (2003). Toward an understanding of definitions and measures of school engagement and related terms. The California School Psychologist, 8(1), 7-27. https://doi.org/10.1007/BF03340893

Joffe, M. M., Ten Have, T. R., Feldman, H. I., \& Kimmel, S. E. (2004). Model selection, confounder control, and marginal structural models. The American Statistician, 58(4), 272-279. https://doi.org/10.1198/000313004X5824

Johnson, M. K., Crosnoe, R., \& Elder Jr, G. H. (2001). Students' attachment and academic engagement: The role of race and ethnicity. Sociology of Education, 318-340. https://doi.org/10.2307/2673138 
Kelly, S., \& Price, H. (2011). The correlates of tracking policy: Opportunity hoarding, status competition, or a technicalfunctional explanation? American Educational Research Journal, 48(3), 560-585. https://doi.org/10.3102/0002831210395927

Kerr, S. P., Pekkarinen, T., \& Uusitalo, R. (2013). School tracking and development of cognitive skills. Journal of Labor Economics, 31(3), 577-602. https://doi.org/10.1086/669493

Kloosterman, R., Ruiter, S., De Graaf, P. M., \& Kraaykamp, G. (2009). Parental education, children's performance and the transition to higher secondary education: trends in primary and secondary effects over five Dutch school cohorts (196599). The British Journal of Sociology, 60(2), 377-398. https://doi.org/10.1111/j.1468-4446.2009.01235.x Korthals, R. A., \& Dronkers, J. (2016). Selection on performance and tracking. Applied Economics, 48(30), 2836-2851. https://doi.org/10.1080/00036846.2015.1130789

Krauss, S., Brunner, M., Kunter, M., Baumert, J., Blum, W., Neubrand, M., \& Jordan, A. (2008). Pedagogical content knowledge and content knowledge of secondary mathematics teachers. Journal of Educational Psychology, 100(3), 716725. https://doi.org/10.1037/0022-0663.100.3.716

Kuhn, M., Weston, S., Wing, J., \& Forester, J. (2016). The contrast 
package. CRAN Package Repository, 1-14.

Kunter, M., \& Baumert, J. (2006). Who is the expert? Construct and criteria validity of student and teacher ratings of instruction. Learning Environments Research, 9(3), 231-251. https://doi.org/10.1007/s10984-006-9015-7

Lacey, C. (1966). Some sociological concomitants of academic streaming in a grammar school. The British Journal of Sociology, 17(3), 245-262. https://doi.org/10.2307/588773

Lavrijsen, J., \& Nicaise, I. (2015). New empirical evidence on the effect of educational tracking on social inequalities in reading achievement. European Educational Research Journal, 14(3), 206-221. https://doi.org/10.1177/1474904115589039

Lee, B. K., Lessler, J., \& Stuart, E. A. (2011). Weight trimming and propensity score weighting. PloS ONE, 6(3), 1-6. https://doi.org/10.1371/journal.pone.0018174

Liang, K.-Y., \& Zeger, S. L. (1986). Longitudinal data analysis using generalized linear models. Biometrika, 73(1), 13-22. https://doi.org/10.1093/biomet/73.1.13

LiSO-project. (2018). Het LiSO-project kort samengevat [The LiSO-project summarized]. Retrieved March 30, 2018, from https://lisoproject.be/

Liu, W. C., Wang, C. K. J., \& Parkins, E. J. (2005). A longitudinal study of students' academic self-concept in a streamed setting: 
The Singapore context. British Journal of Educational Psychology, 75(4), 567-586.

https://doi.org/10.1348/000709905X42239

Maaz, K., Trautwein, U., Lüdtke, O., \& Baumert, J. (2008).

Educational transitions and differential learning

environments: How explicit between-school tracking

contributes to social inequality in educational outcomes. Child

Development Perspectives, 2(2), 99-106.

https://doi.org/10.1111/j.1750-8606.2008.00048.x

Malamud, O., \& Pop-Eleches, C. (2011). School tracking and access to higher education among disadvantaged groups. Journal of Public Economics, 95(11-12), 1538-1549. https://doi.org/j.jpubeco.2011.03.006

Marks, G. N. (2005). Cross-national differences and accounting for social class inequalities in education. International Sociology, 20(4), 483-505. https://doi.org/10.1177/0268580905058328

Marsh, H. W., Ellis, L. A., Parada, R. H., Richards, G., \& Heubeck, B. G. (2005). A short version of the Self Description Questionnaire II: Operationalizing criteria for short-form evaluation with new applications of confirmatory factor analyses. Psychological Assessment, 17(1), 81-102. https://doi.org/10.1037/1040-3590.17.1.81

Marsh, H. W., \& O’Neill, R. (1984). Self Description 
Questionnaire III: The construct validity of multidimensional self-concept ratings by late adolescents. Journal of Educational Measurement, 21(2), 153-174. https://doi.org/10.1111/j.1745-3984.1984.tb00227.x Martin, A. J., Anderson, J., Bobis, J., Way, J., \& Vellar, R. (2012). Switching on and switching off in mathematics: An ecological study of future intent and disengagement among middle school students. Journal of Educational Psychology, 104(1), 1-18. https://doi.org/10.1037/a0025988

McCaffrey, D. F., Ridgeway, G., \& Morral, A. (2004). Propensity score estimation with boosted regression for evaluating causal effects in observational studies. Psychological Methods, 9(4), 403-425. https://doi.org/10.1037/1082-989X.9.4.403

Meece, J. L., Blumenfeld, P. C., \& Hoyle, R. H. (1988). Students' goal orientations and cognitive engagement in classroom activities. Journal of Educational Psychology, 80(4), 514523. https://doi.org/10.1037//0022-0663.80.4.514

Moodie, E. E. M., Delaney, J. A. C., Lefebvre, G., \& Platt, R. W. (2008). Missing confounding data in marginal structural models: A comparison of inverse probability weighting and multiple imputation. The International Journal of Biostatistics, 4(1), 1-23. https://doi.org/10.2202/15574679.1106 
Mulkey, L. M., Catsambis, S., Steelman, L. C., \& Crain, R. L. (2005). The long-term effects of ability grouping in mathematics: A national investigation. Social Psychology of Education, 8(2), 137-177. https://doi.org/10.1007/s11218005-4014-6

Müller, C. M., \& Hofmann, V. (2016). Does being assigned to a low school track negatively affect psychological adjustment? A longitudinal study in the first year of secondary school. School Effectiveness and School Improvement, 27(2), 95-115. https://doi.org/10.1080/09243453.2014.980277

Myers, J. A., Rassen, J. A., Gagne, J. J., Huybrechts, K. F., Schneeweiss, S., Rothman, K. J., ... Glynn, R. J. (2011). Effects of adjusting for instrumental variables on bias and precision of effect estimates. American Journal of Epidemiology, 174(11), 1213-1222. https://doi.org/10.1093/aje/kwr364

OECD. (2012). Equity and Quality in Education. Paris, France: OECD. https://doi.org/10.1787/9789264130852-en OECD. (2016). Netherlands 2016: Foundations for the Future, Reviews of National Policies for Education. Paris, France: OECD Publishing. https://doi.org/10.1787/9789264257658-en Piopiunik, M. (2014). The effects of early tracking on student performance: Evidence from a school reform in Bavaria. 
Economics of Education Review, 42, 12-33.

https://doi.org/10.1016/j.econedurev.2014.06.002

Preckel, F., \& Brüll, M. (2010). The benefit of being a big fish in a big pond: Contrast and assimilation effects on academic selfconcept. Learning and Individual Differences, 20(5), 522531. https://doi.org/10.1016/j.lindif.2009.12.007

Reeve, J. (2012). A self-determination theory perspective on student engagement. In S. L. Christenson, A. L. Reschly, \& C. Wylie (Eds.), Handbook of research on student engagement (pp. 149-172). Springer.

Reschly, A. L., Huebner, E. S., Appleton, J. J., \& Antaramian, S. (2008). Engagement as flourishing: The contribution of positive emotions and coping to adolescents' engagement at school and with learning. Psychology in the Schools, 45(5), 419-431. https://doi.org/10.1002/pits.20306

Retelsdorf, J., Becker, M., Köller, O., \& Möller, J. (2012). Reading development in a tracked school system: A longitudinal study over 3 years using propensity score matching. British Journal of Educational Psychology, 82(4), 647-671. https://doi.org/10.1111/j.2044-8279.2011.02051.x Retelsdorf, J., Butler, R., Streblow, L., \& Schiefele, U. (2010). Teachers' goal orientations for teaching: Associations with instructional practices, interest in teaching, and burnout. 
Learning and Instruction, 20(1), 30-46.

https://doi.org/10.1016/j.learninstruc.2009.01.001

Ridgeway, G., McCaffrey, D. F., Morral, A., Griffin, B. A., \&

Burgette, L. (2017). twang: Toolkit for weighting and analysis of nonequivalent groups. CRAN Package Repository, 1-32.

Robins, J. M., \& Hernán, M. A. (2009). Estimation of the causal effects of time-varying exposures. In G. Fitzmaurice, M.

Davidian, G. Verbeke, \& G. Molenberghs (Eds.), Longitudinal data analysis (pp. 553-599). Boca Raton, FL: Chapman and Hall/CRC.

Robins, J. M., Hernan, M. A., \& Brumback, B. (2000). Marginal structural models and causal inference in epidemiology. Epidemiology, 11(5), 550-560. https://doi.org/10.1097/00001648-200009000-00011

Rosenbaum, P. R., \& Rubin, D. B. (1983). The central role of the propensity score in observational studies for causal effects. Biometrika, 70(1), 41-55. https://doi.org/10.1093/biomet/70.1.41

Rubin, D. B. (1987). Multiple imputation for nonresponse in surveys. New York City, NY: Wiley.

Rubin, D. B. (2001). Using propensity scores to help design observational studies: Application to the tobacco litigation. Health Services and Outcomes Research Methodology, 2(3- 
4), 169-188. https://doi.org/10.1023/A:1020363010465

Ryan, R. M., \& Connell, J. P. (1989). Perceived locus of causality and internalization: examining reasons for acting in two domains. Journal of Personality and Social Psychology, 57(5), 749-761. https://doi.org/10.1037/0022-3514.57.5.749

Salmela-Aro, K., Kiuru, N., \& Nurmi, J.-E. (2008). The role of educational track in adolescents' school burnout: A longitudinal study. British Journal of Educational Psychology, 78(4), 663-689.

https://doi.org/10.1348/000709908X281628

Schafer, J. L., \& Graham, J. W. (2002). Missing data: Our view of the state of the art. Psychological Methods, 7(2), 147-177. https://doi.org/10.1037/1082-989X.7.2.147

Schütz, G., Ursprung, H. W., \& Wößmann, L. (2008). Education policy and equality of opportunity. Kyklos, 61(2), 279-308. https://doi.org/10.1002/pits.20306

Shavit, Y., \& Müller, W. (2000). Vocational secondary education, tracking, and social stratification. In M. Hallinan (Ed.), Handbook of the sociology of education (pp. 437-452). New York City, NY: Plenum.

Skinner, E. A., Furrer, C., Marchand, G., \& Kindermann, T. (2008). Engagement and disaffection in the classroom: Part of a larger motivational dynamic? Journal of Educational Psychology, 
100(4), 765-781. https://doi.org/10.1037/a0012840

Skinner, E. A., Kindermann, T. A., \& Furrer, C. J. (2009). A

motivational perspective on engagement and disaffection:

Conceptualization and assessment of children's behavioral

and emotional participation in academic activities in the

classroom. Educational and Psychological Measurement, 69(3), 493-525. https://doi.org/10.1177/0013164408323233

Skinner, E. A., \& Pitzer, J. R. (2012). Developmental dynamics of student engagement, coping, and everyday resilience. In Handbook of research on student engagement (pp. 21-44).

Boston, MA: Springer.

Steiner, P. M., \& Cook, T. D. (2013). Matching and propensity scores. In T. D. Little (Ed.), The oxford handbook of quantitative methods (pp. 237-259). Oxford, United Kingdom: University Press.

Stevens, P. A. J., \& Vermeersch, H. (2010). Streaming in Flemish secondary schools: Exploring teachers' perceptions of and adaptations to students in different streams. Oxford Review of Education, 36(3), 267-284.

https://doi.org/10.1080/03054981003629862

Stuart, E. A. (2010). Matching methods for causal inference: A review and a look forward. Statistical Science: A Review Journal of the Institute of Mathematical Statistics, 25(1), 1- 
21. https://doi.org/10.1214/09-STS313

Tieben, N., de Graaf, P. M., \& de Graaf, N. D. (2010). Changing effects of family background on transitions to secondary education in the Netherlands: Consequences of educational expansion and reform. Research in Social Stratification and Mobility, 28(1), 77-90.

https://doi.org/10.1016/j.rssm.2009.12.004

Trautwein, U., Lüdtke, O., Marsh, H. W., Köller, O., \& Baumert, J. (2006). Tracking, grading, and student motivation: Using group composition and status to predict self-concept and interest in ninth-grade mathematics. Journal of Educational Psychology, 98(4), 788-806. https://doi.org/10.1037/00220663.98 .4 .788

Trautwein, U., Lüdtke, O., Marsh, H. W., \& Nagy, G. (2009). Within-school social comparison: How students perceive the standing of their class predicts academic self-concept. Journal of Educational Psychology, 101(4), 853-866. https://doi.org/10.1037/a0016306

Turner, J. C., Midgley, C., Meyer, D. K., Gheen, M., Anderman, E. M., Kang, Y., \& Patrick, H. (2002). The classroom environment and students' reports of avoidance strategies in mathematics: A multimethod study. Journal of Educational Psychology, 94(1), 88. https://doi.org/10.1037//0022- 
0663.94.1.88

van Buuren, S., \& Groothuis-Oudshoorn, K. (2011). mice:

Multivariate imputation by chained equations in R. Journal of Statistical Software, 45(3), 1-67.

https://doi.org/10.18637/jss.v045.i03

Van de Werfhorst, H. G., \& Mijs, J. J. (2010). Achievement inequality and the institutional structure of educational systems: A comparative perspective. Annual Review of Sociology, 36, 407-428.

https://doi.org/10.1146/annurev.soc.012809.102538

Van Houtte, M. (2004). Tracking effects on school achievement: A quantitative explanation in terms of the academic culture of school staff. American Journal of Education, 110(4), 354388. https://doi.org/10.1086/422790

Van Houtte, M. (2006a). School type and academic culture: evidence for the differentiation--polarization theory. Journal of Curriculum Studies, 38(3), 273-292. https://doi.org/10.1080/00220270500363661

Van Houtte, M. (2006b). Tracking and teacher satisfaction: Role of study culture and trust. The Journal of Educational Research, 99(4), 247-256. https://doi.org/10.3200/JOER.99.4.247-256

Van Houtte, M. (2016). Lower-track students' sense of academic futility: Selection or effect? Journal of Sociology, 52(4), 874- 
889. https://doi.org/10.1177/1440783315600802

Van Houtte, M., \& Stevens, P. A. (2015). Tracking and sense of futility: the impact of between-school tracking versus withinschool tracking in secondary education in Flanders (Belgium). British Educational Research Journal, 41(5), 782-800. https://doi.org/10.1002/berj.3172

Vandecandelaere, M., Vansteelandt, S., De Fraine, B., \& Van Damme, J. (2016). Time-varying treatments in observational studies: Marginal structural models of the effects of early grade retention on math achievement. Multivariate Behavioral Research, 51(6), 843-864. https://doi.org/10.1080/00273171.2016.1155146

Vorst, H. C. M., \& Smits, J. A. E. (2010). Schoolvragenlijst voor basisonderwijs en voortgezet onderwijs [School questionnaire for primary education and secondary education]. Nijmegen, the Netherlands: Berkhout.

Waldinger, F. (2007). Does ability tracking exacerbate the role of family background for students' test scores. Unpublished Manuscript.

Wang, M.-T., \& Eccles, J. S. (2012). Adolescent behavioral, emotional, and cognitive engagement trajectories in school and their differential relations to educational success. Journal of Research on Adolescence, 22(1), 31-39. 
https://doi.org/10.1111/j.1532-7795.2011.00753.x

Wang, M.-T., \& Fredricks, J. A. (2014). The reciprocal links between school engagement, youth problem behaviors, and school dropout during adolescence. Child Development, 85(2), 722-737. https://doi.org/10.1111/cdev.12138

Wang, M.-T., \& Holcombe, R. (2010). Adolescents' perceptions of school environment, engagement, and academic achievement in middle school. American Educational Research Journal, 47(3), 633-662. https://doi.org/10.3102/0002831209361209

Warm, T. A. (1989). Weighted likelihood estimation of ability in item response theory. Psychometrika, 54(3), 427-450. https://doi.org/10.1007/BF02294627

Wolbers, M. H. J. (2007). Patterns of labour market entry: a comparative perspective on school-to-work transitions in 11 European countries. Acta Sociologica, 50(3), 189-210. https://doi.org/10.1177/0001699307080924

Wößmann, L. (2008). Efficiency and equity of European education and training policies. International Tax and Public Finance, 15(2), 199-230. https://doi.org/10.1177/0001699307080924

Wylie, C., \& Hodgen, E. (2012). Trajectories and patterns of student engagement: Evidence from a longitudinal study. In S. L. Christenson, A. L. Reschly, \& C. Wylie (Eds.), Handbook of research on student engagement (pp. 585-599). Boston, 
MA: Springer US. 
Table 1

Descriptions, information sources and properties of time-varying and time-fixed confounder measures

\begin{tabular}{|c|c|c|c|c|c|c|}
\hline Variable & Description & Info & T0 & $\mathrm{T} 1$ & $\mathrm{~T} 2$ & $\begin{array}{ll}\text { T3 } & \text { T4 }\end{array}$ \\
\hline Mathematics & IRT-score achievement in mathematics & AT & $\mathrm{X}$ & $\mathrm{X}$ & $\mathrm{X}$ & $\mathrm{X}$ \\
\hline Dutch & IRT-score achievement in Dutch reading comprehension & AT & $\mathrm{X}$ & & & \\
\hline French & IRT-score achievement in French & AT & $\mathrm{X}$ & & & \\
\hline Gender & Indicator for boy & OR & $\mathrm{X}$ & & & \\
\hline Age & Indicator whether student is older than normally progressing & OR & $\mathrm{X}$ & & & \\
\hline SES & Factor score socioeconomic status & PQ & $\mathrm{X}$ & & & \\
\hline Allowance & Indicator whether family has an allowance due to low income & OR & $\mathrm{X}$ & & & \\
\hline Education mother & Indicator whether mother is lowly educated & OR & $\mathrm{X}$ & & & \\
\hline Other language & Indicator whether the home language is not Dutch & OR & $\mathrm{X}$ & & & \\
\hline Global self-concept & Factor score global academic self-concept & SQ & $\mathrm{X}$ & $\mathrm{X}$ & $\mathrm{X}$ & $\mathrm{X}$ \\
\hline Self-concept mathematics & Factor score self-concept mathematics & SQ & $\mathrm{X}$ & $\mathrm{X}$ & $\mathrm{X}$ & $\mathrm{X}$ \\
\hline Self-concept Dutch & Factor score self-concept Dutch & SQ & $\mathrm{X}$ & $\mathrm{X}$ & $\mathrm{X}$ & $\mathrm{X}$ \\
\hline Self-concept French & Factor score self-concept French & SQ & $X$ & $X$ & $X$ & \\
\hline
\end{tabular}




\begin{tabular}{|c|c|c|c|c|c|c|c|}
\hline Variable & Description & Info & T0 & $\mathrm{T} 1$ & $\mathrm{~T} 2$ & T3 & T4 \\
\hline Wellbeing & Factor score wellbeing & SQ & $\mathrm{X}$ & $\mathrm{X}$ & $\mathrm{X}$ & $\mathrm{X}$ & \\
\hline Mindset & Factor score mindset & SQ & $\mathrm{X}$ & $\mathrm{X}$ & $\mathrm{X}$ & $\mathrm{X}$ & \\
\hline Autonomous motivation & Factor score autonomous motivation & SQ & $\mathrm{X}$ & $\mathrm{X}$ & $\mathrm{X}$ & $\mathrm{X}$ & \\
\hline Controlled motivation & Factor score controlled motivation & SQ & $\mathrm{X}$ & $\mathrm{X}$ & $\mathrm{X}$ & $\mathrm{X}$ & \\
\hline Behavioural engagement & Factor score behavioural engagement & SQ & $\mathrm{X}$ & $X$ & $\mathrm{X}$ & $\mathrm{X}$ & $\mathrm{X}$ \\
\hline Emotional engagement & Factor score emotional engagement & SQ & $\mathrm{X}$ & $\mathrm{X}$ & $\mathrm{X}$ & $\mathrm{X}$ & $\mathrm{X}$ \\
\hline Behavioural disengagement & Factor score behavioural disengagement & SQ & $X$ & $X$ & $\mathrm{X}$ & $\mathrm{X}$ & \\
\hline Emotional disengagement & Factor score emotional disengagement & SQ & $\mathrm{X}$ & $\mathrm{X}$ & $\mathrm{X}$ & $\mathrm{X}$ & \\
\hline Interest mathematics & Sum score interest in mathematics & SQ & $\mathrm{X}$ & $X$ & $\mathrm{X}$ & $\mathrm{X}$ & \\
\hline Interest Dutch & Sum score interest in Dutch & SQ & $\mathrm{X}$ & $\mathrm{X}$ & $\mathrm{X}$ & $\mathrm{X}$ & \\
\hline Interest French & Sum score interest in French & SQ & $X$ & $X$ & $X$ & & \\
\hline Interest technology & Sum score interest in technology & SQ & $\mathrm{X}$ & $X$ & $X$ & $X$ & \\
\hline
\end{tabular}

Note: $\mathrm{T} 0=$ measured at $\mathrm{T} 0 ; \mathrm{T} 1=$ measured at $\mathrm{T} 1 ; \mathrm{T} 2=$ measured at $\mathrm{T} 2 ; \mathrm{T} 3=$ measured at $\mathrm{T} 3 ; \mathrm{T} 4=$ measured at $\mathrm{T} 4 ; \mathrm{AT}=$ achievement test; $\mathrm{OR}=$ official records; $\mathrm{PQ}=$ parent questionnaire; $\mathrm{SQ}=$ student questionnaire 
Table 2

Overview treatment histories of classical and modern track comparison, modern and technical track comparison, and technical and vocational track comparison

\begin{tabular}{|c|c|c|c|c|}
\hline Treatment history & $\mathrm{T} 1$ & $\mathrm{~T} 2$ & T3 & $\mathrm{T} 4$ \\
\hline \multicolumn{5}{|l|}{ Classical and modern track comparison } \\
\hline Classical track continuous $(0,0,0,0)$ & 1240 & 978 & 673 & 608 \\
\hline Classical to modern after T3 $(0,0,0,1)$ & & & & 61 \\
\hline Classical to modern after T2 $(0,0,1,1)$ & & & 291 & 281 \\
\hline Classical to modern after $\mathrm{T} 1(0,1,1,1)$ & & 242 & 223 & 196 \\
\hline Modern track continuous $(1,1,1,1)$ & 955 & 881 & 728 & 652 \\
\hline To other program & & 94 & 280 & 397 \\
\hline \multicolumn{5}{|l|}{ Modern and technical track comparison } \\
\hline Modern track continuous $(0,0,0,0)$ & 2182 & 1780 & 1304 & 1078 \\
\hline Modern to technical track T3 $(0,0,0,1)$ & & & & 187 \\
\hline Modern to technical track T2 $(0,0,1,1)$ & & & 338 & 315 \\
\hline Modern to technical track $\mathrm{T} 1(0,1,1,1)$ & & 284 & 219 & 192 \\
\hline Technical track continuous $(1,1,1,1)$ & 887 & 691 & 586 & 541 \\
\hline To other program & & 314 & 622 & 756 \\
\hline \multicolumn{5}{|l|}{ Technical and vocational track comparison } \\
\hline Technical track continuous $(0,0,0,0)$ & 1026 & 772 & 645 & 588 \\
\hline Technical to vocational track T3 $(0,0,0,1)$ & & & & 44 \\
\hline
\end{tabular}




\begin{tabular}{ccccc}
\hline Treatment history & T1 & T2 & T3 & T4 \\
\hline Technical to vocational track T2 $(0,0,1,1)$ & & & 89 & 86 \\
Technical to vocational track T1 $(0,1,1,1)$ & & 162 & 143 & 139 \\
Vocational track continuous $(1,1,1,1)$ & 544 & 497 & 473 & 454 \\
To other program & & 139 & 220 & 259
\end{tabular}

$\overline{\text { Note }: \mathrm{T} 1=\text { Number of students first year after removal extreme propensity scores; } \mathrm{T} 2=\text { Number }}$ of students second year after removal extreme propensity scores; T3 = Number of students third year after removal extreme propensity scores; $\mathrm{T} 4=$ Number of students fourth year after removal extreme propensity scores 
Tables

Table 3

SMDs after weighting

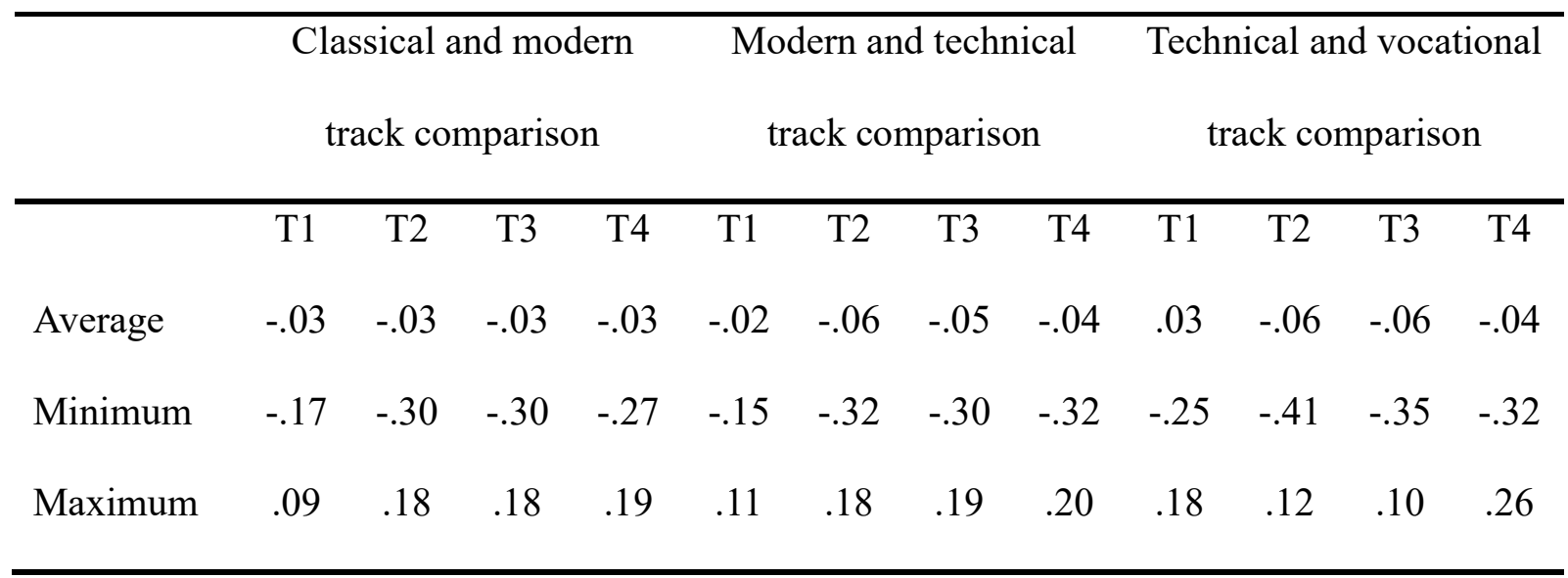

Note: $\mathrm{SMD}=$ standardized mean difference 
Table 4

Contrast estimates behavioural engagement and emotional engagement in classical and modern track comparison

\section{Behavioural engagement Emotional engagement}

\begin{tabular}{|c|c|c|c|c|}
\hline & $d$ & SE & $d$ & SE \\
\hline \multicolumn{5}{|l|}{ T1 } \\
\hline High - low & -0.06 & 0.04 & 0.07 & 0.04 \\
\hline \multicolumn{5}{|l|}{$\mathbf{T 2}$} \\
\hline High - low & 0.02 & 0.05 & 0.05 & 0.04 \\
\hline High - T1 Change & 0.15 & 0.09 & $0.21 *$ & 0.07 \\
\hline \multicolumn{5}{|l|}{ T3 } \\
\hline High - low & -0.01 & 0.07 & 0.09 & 0.05 \\
\hline High - T1 Change & $0.27 *$ & 0.09 & $0.28 *$ & 0.07 \\
\hline High - T2 Change & $0.18^{*}$ & 0.09 & $0.15^{*}$ & 0.07 \\
\hline \multicolumn{5}{|l|}{ T4 } \\
\hline High - low & 0.00 & 0.07 & 0.06 & 0.06 \\
\hline High - T1 Change & $0.19 *$ & 0.09 & $0.28 *$ & 0.08 \\
\hline High - T2 Change & 0.17 & 0.09 & $0.23 *$ & 0.08 \\
\hline High - T3 Change & 0.14 & 0.15 & 0.19 & 0.14 \\
\hline
\end{tabular}

Note: $d=$ contrast estimate; high = continuously in the higher track; low = continuously in the lower track; $\mathrm{T} 1$ change $=$ changed from higher to lower track after $\mathrm{T} 1 ; \mathrm{T} 2$ change $=$ changed from higher to lower track after T2; T3 change $=$ changed from higher to lower track after T3 
Table 5

Contrast estimates behavioural engagement and emotional engagement in modern and technical track comparison

\section{Behavioural engagement $\quad$ Emotional engagement}

\begin{tabular}{|c|c|c|c|c|}
\hline & $d$ & $\mathrm{SE}$ & $d$ & $\mathrm{SE}$ \\
\hline \multicolumn{5}{|l|}{$\mathbf{T 1}$} \\
\hline High - low & -0.03 & 0.04 & 0.01 & 0.04 \\
\hline \multicolumn{5}{|l|}{$\mathbf{T} 2$} \\
\hline High - low & -0.03 & 0.05 & 0.07 & 0.04 \\
\hline High - T1 Change & $0.20 *$ & 0.09 & 0.08 & 0.07 \\
\hline \multicolumn{5}{|l|}{ T3 } \\
\hline High - low & -0.01 & 0.06 & 0.08 & 0.06 \\
\hline High - T1 Change & 0.09 & 0.10 & 0.11 & 0.08 \\
\hline High - T2 Change & 0.08 & 0.08 & -0.04 & 0.07 \\
\hline \multicolumn{5}{|l|}{ T4 } \\
\hline High - low & 0.03 & 0.07 & 0.12 & 0.06 \\
\hline High - T1 Change & 0.19 & 0.11 & $0.18^{*}$ & 0.09 \\
\hline High - T2 Change & $0.17^{*}$ & 0.08 & 0.01 & 0.08 \\
\hline High - T3 Change & 0.07 & 0.11 & 0.03 & 0.09 \\
\hline
\end{tabular}

Note: $d=$ contrast estimate; high = continuously in the higher track; low = continuously in the lower track; T1 change $=$ changed from higher to lower track after T1; T2 change $=$ changed from higher to lower track after T2; T3 change $=$ changed from higher to lower track after T3 
Table 6

Contrast estimates behavioural engagement and emotional engagement in technical and vocational track comparison

\begin{tabular}{|c|c|c|c|c|}
\hline & \multicolumn{2}{|c|}{ Behavioural engagement } & \multicolumn{2}{|c|}{ Emotional engagement } \\
\hline & $d$ & $\mathrm{SE}$ & $d$ & $\mathrm{SE}$ \\
\hline \multicolumn{5}{|l|}{$\mathbf{T 1}$} \\
\hline High - low & 0.07 & 0.10 & -0.01 & 0.11 \\
\hline \multicolumn{5}{|l|}{$\mathbf{T 2}$} \\
\hline High - low & $0.22 *$ & 0.10 & $0.18^{*}$ & 0.08 \\
\hline High - T1 Change & 0.38 & 0.26 & 0.18 & 0.23 \\
\hline \multicolumn{5}{|l|}{ T3 } \\
\hline High - low & -0.10 & 0.12 & -0.03 & 0.10 \\
\hline High - T1 Change & 0.17 & 0.15 & 0.15 & 0.13 \\
\hline High - T2 Change & -0.31 & 0.31 & -0.30 & 0.23 \\
\hline \multicolumn{5}{|l|}{ T4 } \\
\hline High - low & -0.11 & 0.13 & 0.04 & 0.12 \\
\hline High - T1 Change & -0.16 & 0.16 & -0.10 & 0.14 \\
\hline High - T2 Change & -0.16 & 0.16 & -0.13 & 0.13 \\
\hline High - T3 Change & 0.05 & 0.44 & 0.07 & 0.24 \\
\hline
\end{tabular}

Note: $d=$ contrast estimate; high = continuously in the higher track; low = continuously in the lower track; $\mathrm{T} 1$ change $=$ changed from higher to lower track after $\mathrm{T} 1 ; \mathrm{T} 2$ change $=$ changed from higher to lower track after T2; T3 change $=$ changed from higher to lower track after T3 
Timeline assessment occasions and school years.

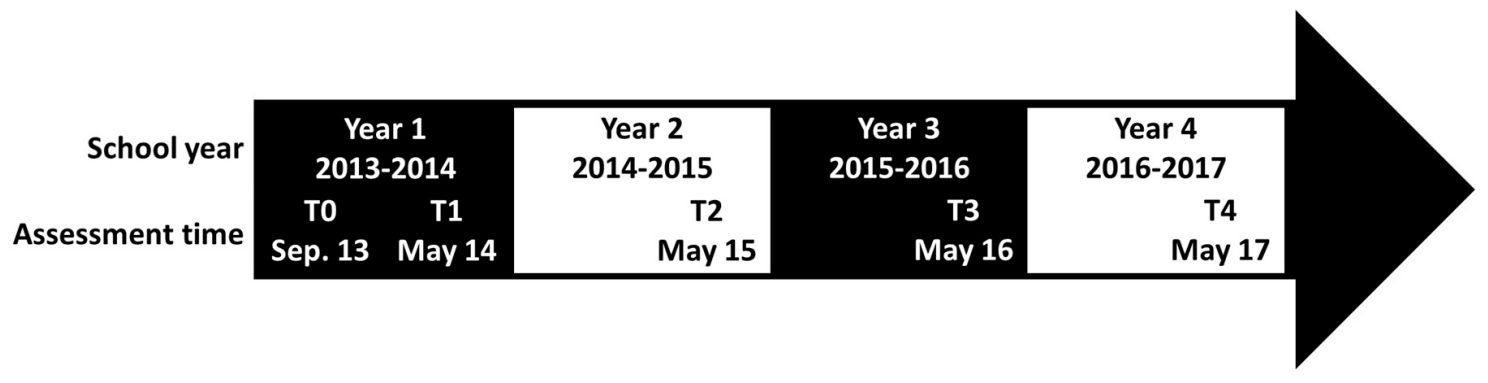

Figure 1. 
Overlap in logit propensity scores for higher track allocation across treatment histories of each track comparison.
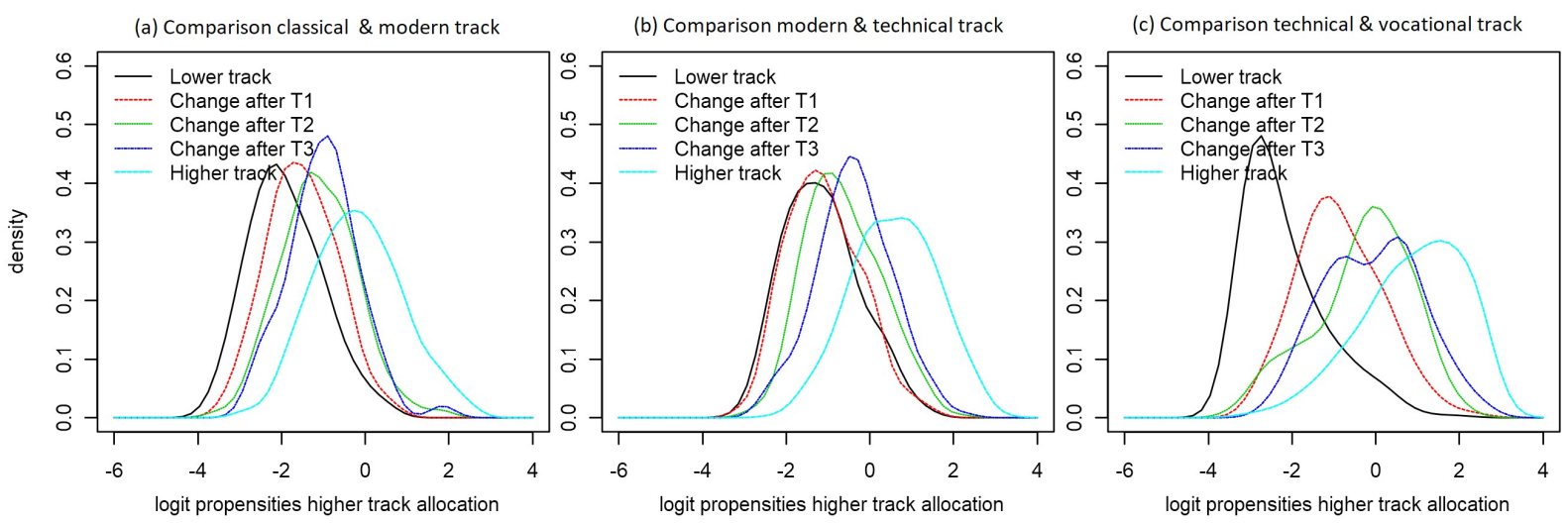

Figure 2. 
SMDs classical and modern track comparison at T1, T2, T3 and T4.
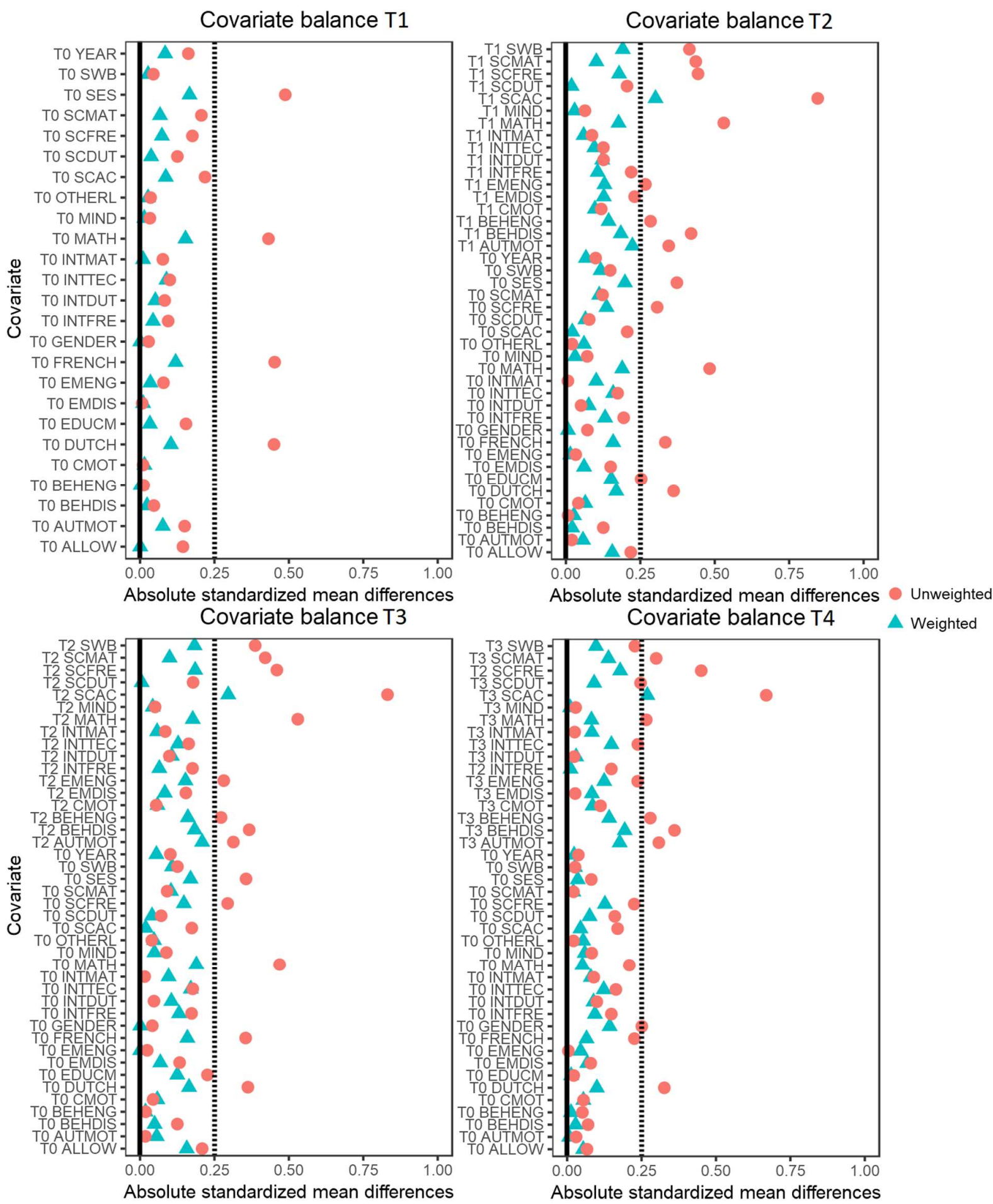

Figure 3. 
SMDs modern and technical track comparison at T1, T2, T3 and T4.
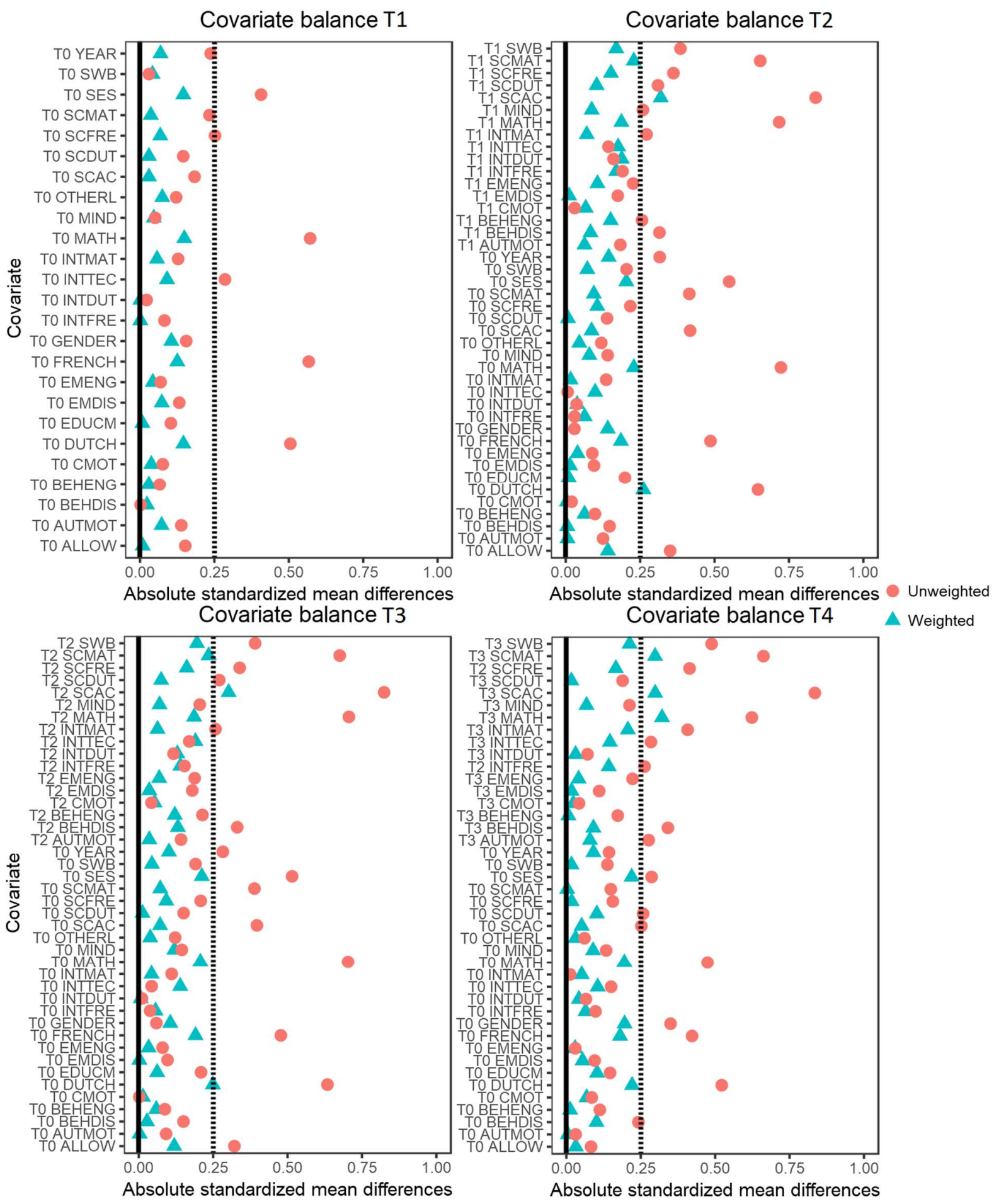

Figure 4. 
SMDs technical and vocational track comparison at T1, T2, T3 and T4.
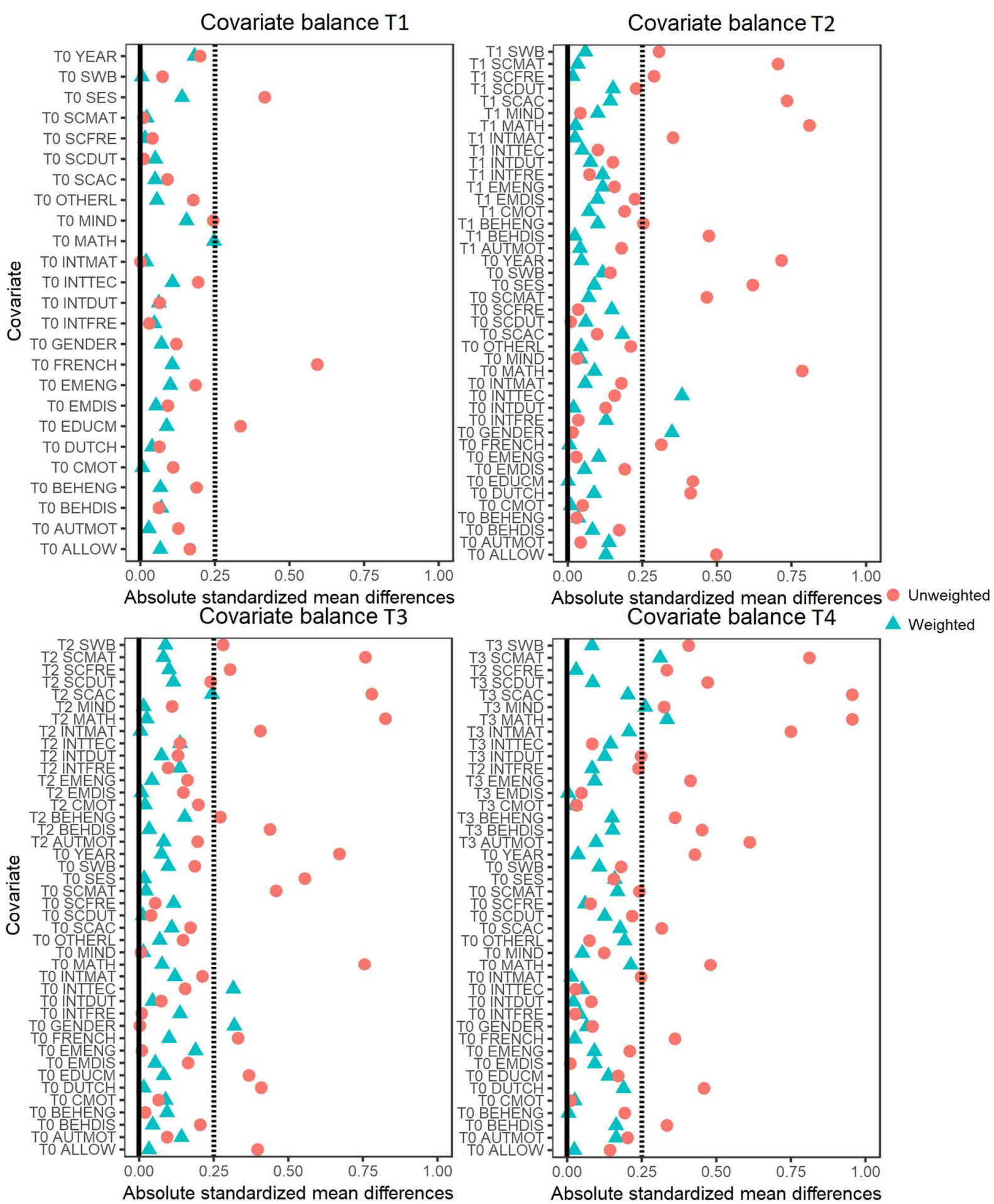

Figure 5. 
Development behavioural engagement and emotional engagement in classical and modern track comparison.

(a) Behavioral engagement

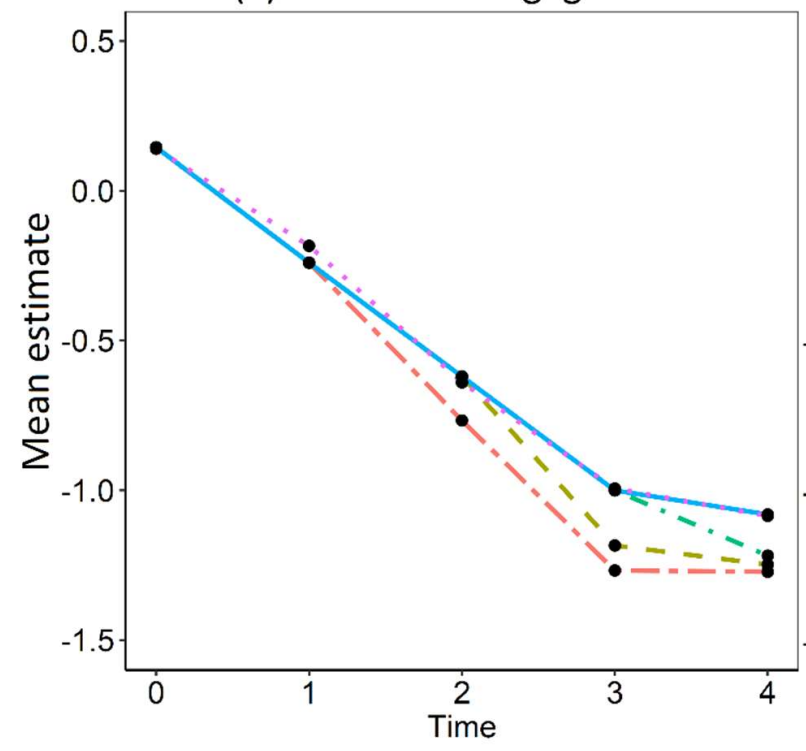

(b) Emotional engagement

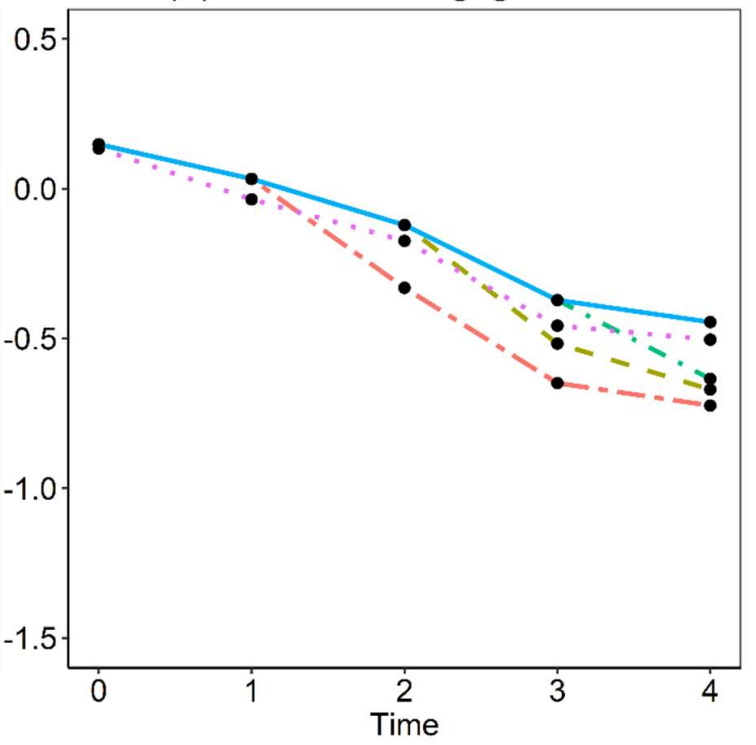

-High Track - Low Track--High to low T1- High to low T2 - -High to low T3

Figure 6. 
Development behavioural engagement and emotional engagement in modern and technical track comparison.

(a) Behavioral engagement

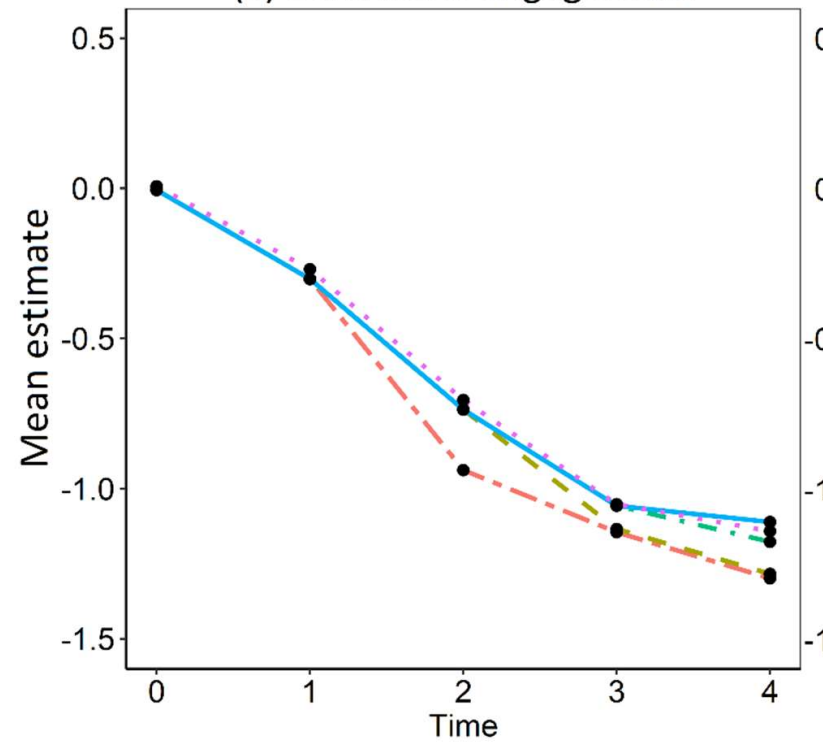

(b) Emotional engagement

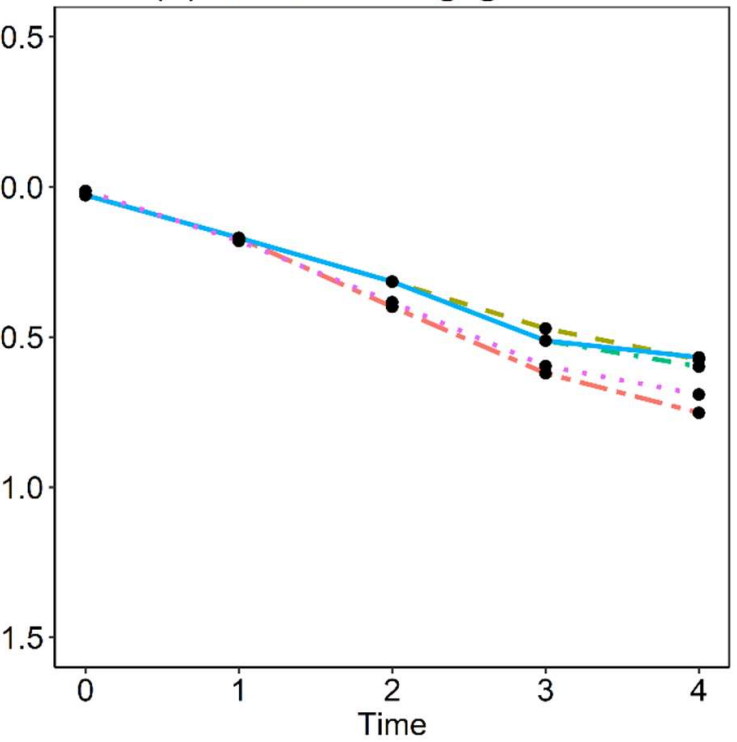

-High Track - Low Track--High to low T1- High to low T2" -High to low T3

Figure 7. 
Development behavioural engagement and emotional engagement in technical and vocational track comparison.

(a) Behavioral engagement

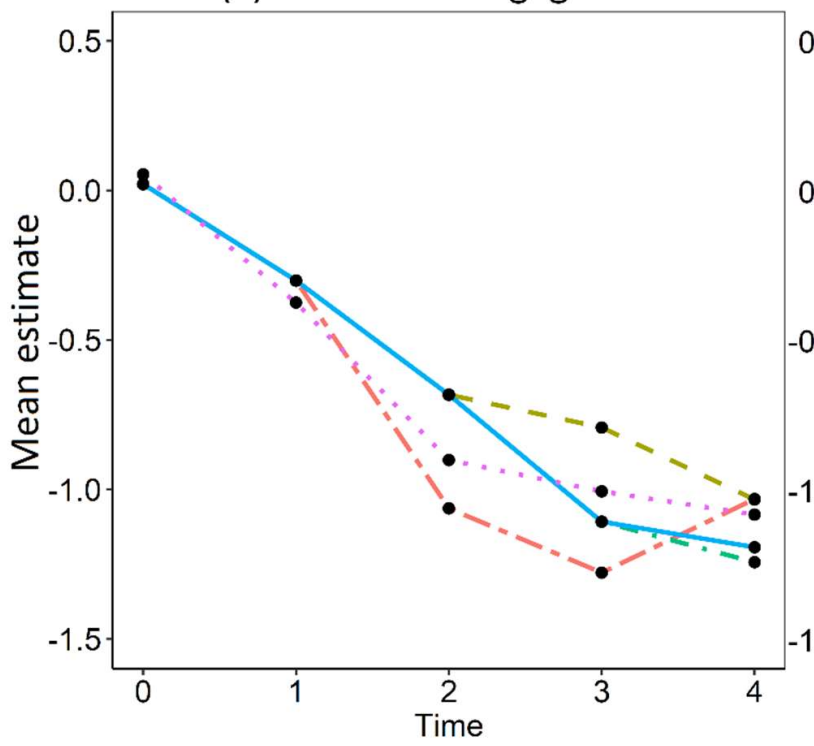

(b) Emotional engagement

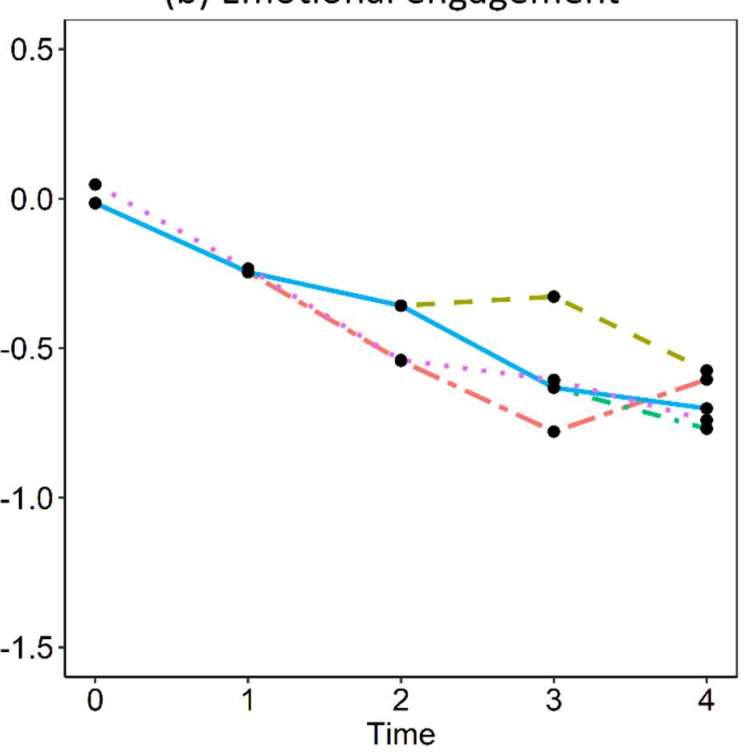

-High Track " Low Track"--High to low T1- High to low T2" -High to low T3

Figure 8 . 